\title{
Review
}

\section{Wearable Actuators: An Overview}

\author{
Yu Chen ${ }^{1}$, Yiduo Yang ${ }^{1}$, Mengjiao $\mathrm{Li}^{2}$, Erdong Chen ${ }^{2}$, Weilei Mu ${ }^{2} \mathbb{D}$, Rosie Fisher ${ }^{1}$ and Rong Yin ${ }^{1, *} \mathbb{C}$ \\ 1 Textile Engineering, Chemistry and Science, Wilson College of Textiles, North Carolina State University, \\ Raleigh, NC 27695, USA; ychen242@ncsu.edu (Y.C.); yyang72@ncsu.edu (Y.Y.); arfishe3@ncsu.edu (R.F.) \\ 2 College of Engineering, Ocean University of China, Qingdao 266100, China; limengjiao567@163.com (M.L.); \\ cchenerdong@163.com (E.C.); muweilei@ouc.edu.cn (W.M.) \\ * Correspondence: ryin@ncsu.edu
}

check for

updates

Citation: Chen, Y.; Yang, Y.; Li, M.; Chen, E.; Mu, W.; Fisher, R.; Yin, R. Wearable Actuators: An Overview. Textiles 2021, 1, 283-321. https: / / doi.org/10.3390/textiles1020015

Academic Editor: Ivo Grabchev

Received: 1 June 2021

Accepted: 20 August 2021

Published: 24 August 2021

Publisher's Note: MDPI stays neutral with regard to jurisdictional claims in published maps and institutional affiliations.

Copyright: (c) 2021 by the authors. Licensee MDPI, Basel, Switzerland. This article is an open access article distributed under the terms and conditions of the Creative Commons Attribution (CC BY) license (https:/ / creativecommons.org/licenses/by/ $4.0 /)$.

\begin{abstract}
The booming wearable market and recent advances in material science has led to the rapid development of the various wearable sensors, actuators, and devices that can be worn, embedded in fabric, accessorized, or tattooed directly onto the skin. Wearable actuators, a subcategory of wearable technology, have attracted enormous interest from researchers in various disciplines and many wearable actuators and devices have been developed in the past few decades to assist and improve people's everyday lives. In this paper, we review the actuation mechanisms, structures, applications, and limitations of recently developed wearable actuators including pneumatic and hydraulic actuators, shape memory alloys and polymers, thermal and hygroscopic materials, dielectric elastomers, ionic and conducting polymers, piezoelectric actuators, electromagnetic actuators, liquid crystal elastomers, etc. Examples of recent applications such as wearable soft robots, haptic devices, and personal thermal regulation textiles are highlighted. Finally, we point out the current bottleneck and suggest the prospective future research directions for wearable actuators.
\end{abstract}

Keywords: smart textiles; wearable; fiber actuators; soft exoskeleton; haptic action

\section{Introduction}

The global wearable market showed a dramatic swell in the past decade with a market size valued at USD 28 billion in 2020 and is expected to expand continually in the next decade. Wearable technology, an emerging trend, integrates sensors, actuators, and electronics that can be worn, embedded in fabric or accessories, or tattooed directly onto the skin to assist daily activities and address changing lifestyles. Wearable actuators, a subcategory of wearable technology, require a compatible modulus to the human body, a huge scope of motion with high precision and velocity, great strain energy density to generate a high force level, a low fatigue rate for a long lifetime, and good reliability.

Conventional actuators including rotary or linear electrical motors, pneumatic and hydraulic actuators [1] provide high power, fast response time, and have been applied in industries for centuries; they are, however, stiff, heavy, noisy, and nonbiological, which limit their applications in wearables. People expect the wearable actuators to be lightweight, inconspicuous, lifelike, and versatile when on the human body, while still achieving their purpose outstandingly. These requirements impelled the development of soft actuation technologies and have attracted enormous interest from researchers in various disciplines [2]. Unlike those traditional actuators, these actuators are small and light, and are not limited to the electrical-mechanical force conversion method. These soft actuators can respond to multiple stimuli such as heat, light, electricity and moisture, exerting force or producing shape changes [2].

Applications of wearable actuators mainly include wearable robotics, haptic devices, and smart textiles. Wearable robotics have been proven valuable in rehabilitation, body assistance, and/or virtual reality [3]. These applications cover systems of various sizes, from millimeter-scale biorobots to large deployable structures. Haptic devices allow the intent 
recognition and information transmission through the interface link between the device and the skin. They contain flexible tactile actuators that can transfer the signal through vibration or morphological change [4]. Smart textiles are textiles that can interact with the environment or respond to stimuli [5,6]. Examples of smart textile applications include electrocardiography-T-shirts/wristbands, electroencephalography caps and photovoltaic curtains [1].

There are several review articles introducing the material and working principles of various soft actuators, but few of them are focused on the scope of wearable actuators $[2,5,7,8]$. In this paper, we review the actuation mechanisms, structures, applications, and limitations of recently developed wearable actuators including pneumatic and hydraulic actuators, shape memory alloys and polymers, thermal and hygroscopic materials, dielectric elastomers, ionic and conducting polymers, piezoelectric actuators, electromagnetic actuators, liquid crystal elastomers, etc. Examples of the recent applications such as wearable soft robots, haptic devices, and personal thermal regulation textiles are highlighted. Finally, we point out the current bottleneck and suggest the prospective future research directions for wearable actuators.

\section{Wearable Actuators: Materials, Structures, Applications, Merits and Limitations}

\subsection{Pneumatic and Hydraulic Actuator}

Artificial muscles are born out of human needs for biological muscles, with a wide range of applications in soft robots, wearable devices, and medicine [9,10]. They are typically demonstrated to be alternatives to rigid electrostatic and electromagnetic actuators, since they possess unique advantages such as being silent, soft, and compliant. Among different forms of artificial muscles, fluid-driven actuators are commonly used due to their simplicity, large driving stress and deformation, good energy efficiency, and processability [11]. By far, pneumatic and hydraulic actuators are one of the most applied actuators in the industry. According to previous research, fluid-driven actuators can be simply divided into three major types of devices: elastic fluidic actuator, piston-cylinder fluidic actuators, and drag-based fluidic actuators [12]. Note that in this review we mainly focus on elastic fluidic actuators, specifically McKibben actuators, since they are by far the most common in wearable actuators [12]. Pneumatic and hydraulic actuators will be introduced together since they share similar structures and mechanisms. Compared to pneumatic, hydraulic actuator systems are more complicated and normally require the installation of a pump, valves, hoses, and an electric motor [13]. Nevertheless, hydraulic motors typically possess the better power to weight ratio [14].

\subsubsection{Structure}

McKibben actuators are typical pneumatic artificial muscles (PAMs). These actuators generally consist of an expandable chamber, normally a balloon, with other structures. By the pressurization of fluid in the chamber, these actuators can transform the expansion to a contraction force. Pneumatic and hydraulic actuators can generate linear, torsional, and bending actuation through the control of internal structures, which are normally inspired by bio-architectures. For example, inspired by muscular hydrostat, Schaffner et al. demonstrated complex motion modes on soft actuators by printing stiff silicone stripes on top of a soft silicone cylinder [15] (Figure 1a). With the arrangement of stiff fiber, this actuator can achieve bending, elongation, and other movements. Similarly, Kim et al. reported a lamina composed of not stretchable fiber, super-elastic matrix, and an adhesive backing [16]. This lamina is also named Stretchable Adhesive Uni-Directional prepreg (STAUD-prepreg) (Figure 1b). By adhering multiple prepreg on a stack, this soft actuator demonstrates complex motion. It is worth noting that with the rearrangement of prepregs, this actuator is reprogrammable, which makes it different than other predefined fluid-driven actuators. Based on vacuum-actuated muscle-inspired pneumatic structures (VAMPs), Li et al. proposed fluid-driven origami-inspired artificial muscles (FOAMs) composed of a folding skeleton, flexible fluid-tight skin, and fluid medium (Figure 1c) [17]. 
Through programing the geometry of the skeleton, various motions and contractions can be achieved. Experiments reveal that these muscles can contract over $90 \%$ of their initial lengths, generate stresses of $\sim 600 \mathrm{kPa}$, and produce peak power densities over $2 \mathrm{~kW} / \mathrm{kg}$.

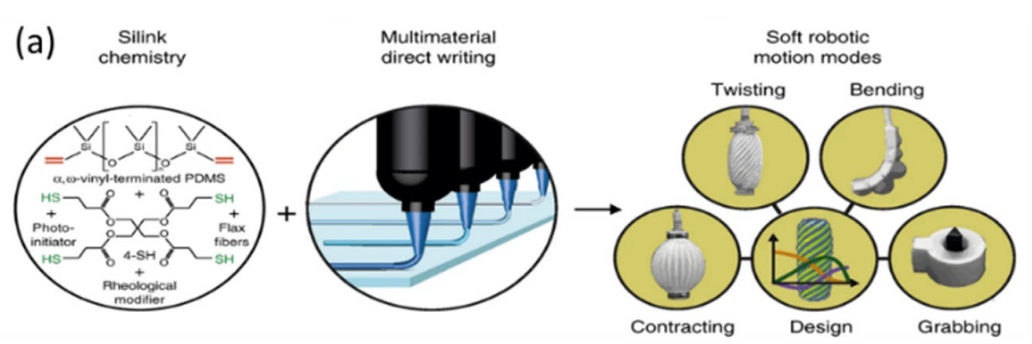

(b)

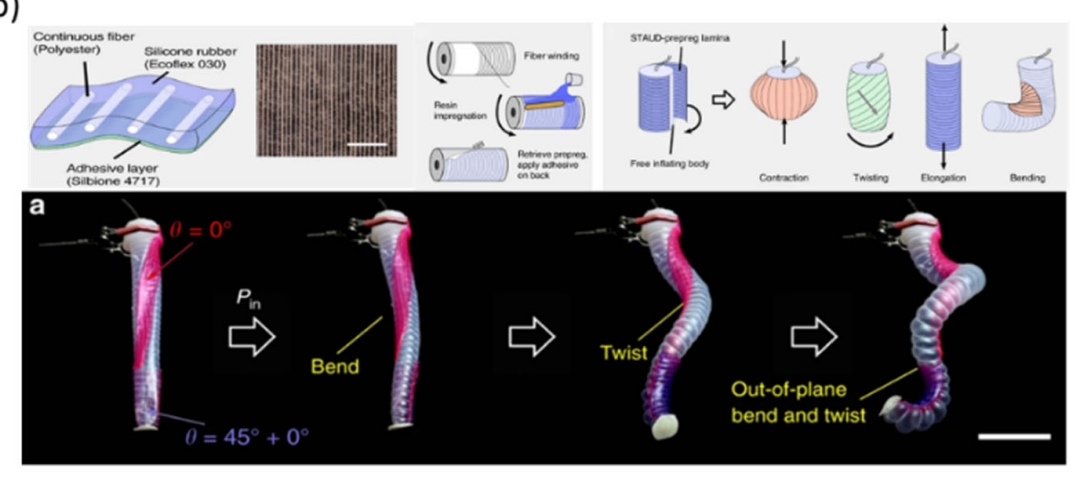

(c)

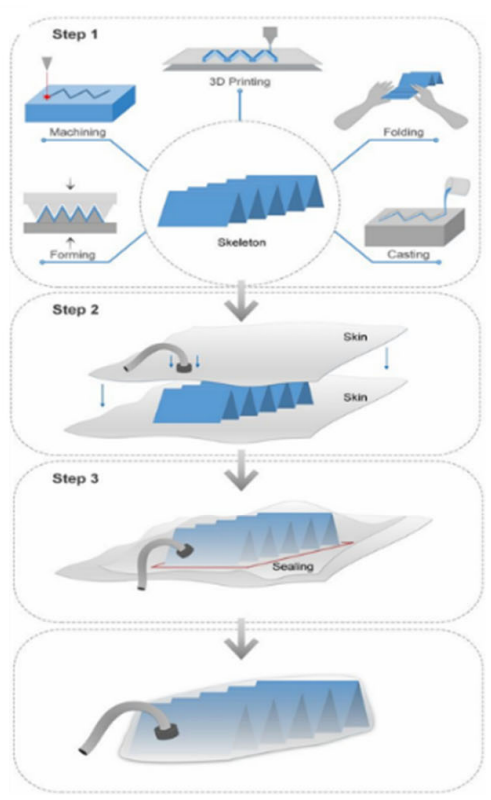

Figure 1. Schematic diagram of structures of pneumatic and hydraulic actuators. (a) Silicone-based 3D-printing pneumatic actuators [15] copyright 2018, the authors, published by Springer Nature. (b) Stretchable Adhesive Uni-Directional prepreg (STAUD-prepreg) [16] copyright 2019, the authors, published by Springer Nature. (c) Fluid-driven origami-inspired artificial muscles (FOAMs) [17] copyright 2017, the author(s), published by PNAS.

\subsubsection{Applications}

A typical application of pneumatic and hydraulic actuators is Robotic orthoses, also called exoskeletons. These devices are usually used to assist human movement, or for rehabilitation of upper or lower limbs [18]. The electric, hydraulic, and pneumatic actuators are the most popular in current orthoses. Here, we briefly introduce some recent research of pneumatic/hydraulic actuators on exoskeleton devices. These devices use simple but well-designed materials with novel actuation mechanisms to achieve lightness and high efficiency.

An inflatable wrinkle pneumatic actuator with fast inflation and deflation responses was proposed [19]. A theoretical model was built to improve the design of the torque required to fit the joints that need to be assisted. A pneumatic circuit was designed to instantly generate negative pressure at the exit of the actuator, thereby shortening the exhaust time. This wrinkle actuator was applied on a wearable knee suit to exhibit rapid inflation and deflation times ( $0.40 \mathrm{~s}$ and $0.16 \mathrm{~s}$ ) (Figure 2a). A textile based pneumatic actuator was designed to assist the movement of the upper arm through shoulder abduction and horizontal flexion/extension [20]. By coordinated movement of Abduction Actuators (ABA) with the Horizontal Extension/Flexion Actuator (HEFA), the device can provide comprehensive support for movement in different directions of the shoulder. With only $0.48 \mathrm{~kg}$ for the whole actuator systems, this device can generate $8 \mathrm{Nm}$ under $70 \mathrm{kpa}$. 
(a)

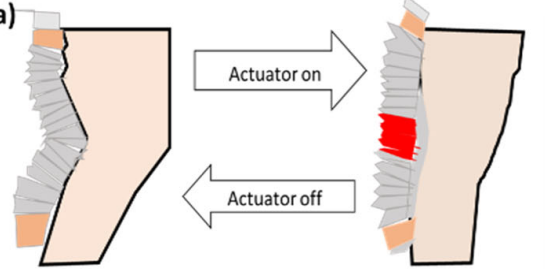

(b)

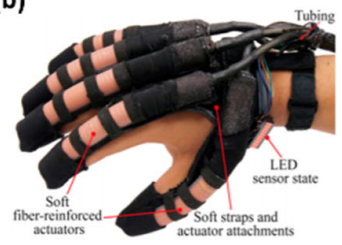

(C)

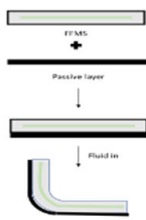

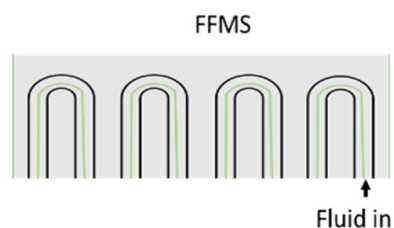

Figure 2. Applications of pneumatic/hydraulic actuators as wearable devices. (a) Pneumatic based wearable knee suit [19]. (b) A hydraulic soft glove for combined assistance and at-home rehabilitation [21]. Copyright 2015, Elsevier. (c) Fluidic Fabric Muscle Sheets (FFMS) [22].

A soft robotic glove based on a fluid-driven actuator demonstrated assistance in the grasping movement of the hand [21]. Different actuation modes for the thumb and the rest of the fingers were applied to achieve a typical grasping movement (Figure 2b). Inspired by sheet-like biological muscles, the Zhu group presented a new family of soft actuators, named Fluidic Fabric Muscle Sheets (FFMS) [22]. The elastic tubes were stitched into fabric to achieve actuation by the movement of fluid in and out. By the design of the fluid route, these actuators exhibit multiple deformation. Through the application of textile technology, this type of actuator can be made into a micro execution unit, or can be developed as a large, meter-level actuator. Data shows that this type of actuator can withstand a force of more than $150 \mathrm{n}$, which is more than 115 times its weight, and up to $100 \%$ engineering strain (Figure 2c).

\subsubsection{Merit and Limitations}

A major problem with pneumatic/hydraulic actuators is poor portability [23]. These actuators usually require a large fluid tank and assorted control units. In addition, the seal of the actuator is also a challenge [24]. Although they are made of soft materials, these actuators still contain some hard parts, which limit their applications. At the same time, their advantages are obvious. The actuation mechanism determines that these actuators are not limited by material. Through the integration of the control system and structure, pneumatic/hydraulic actuators can achieve very complex movements [25]. Fluid pressure can generate a greater driving force than other soft materials, which promise their applications for exoskeletons. Due to the maturity of the process technique, these actuators have been made into commercial products for daily use [26].

\subsection{Shape Memory Effect}

Shape memory effect (SME) is a phenomenon in which a material recovers to its original size and shape when heated above a certain characteristic transformation temperature [27]. The two most prevalent shape-memory materials are shape memory alloys (SMAs) and shape memory polymers (SMPs).

\subsubsection{SMAs}

SMAs are characterized by solid state displacive transformations between austenite and martensite phases in response to a stimulus such as heat. This provides the materials with the capability for sustaining and recovering from strains up to $10 \%$ which imbues them with unique actuator and potential sensor capabilities in smart material systems [28]. As shown in Figure 3, upon heating, phase transformation from martensite to austenite starts at temperature $A_{s}$ and stops at temperature $A_{f}$, whilst the reverse phase transformation starts at temperature $M_{s}$ and stops at temperature $M_{f}$ during cooling (Figure 3a). There are three major shape memory characteristics for SMAs, namely one-way memory effect, two-way memory effect, and pseudoelasticity [29]. In one-way SMAs, the material is deformed at a low temperature, and the shape can be restored after heating, in which the SME only exists in the heating process. In two-way SMAs, the material has SME during both heating and cooling by training. In pseudoelasticity, the phase transition of the material comes from an external mechanical stress instead of thermal excitation. The SME 
was first observed in gold-cadmium alloy by Arne Ölander in 1932 [30]. So far, more than 50 alloy metals with shape memory effect have been found. Among them, Nickel-titanium (NiTi) has become the most popular and studied SMA due to its outstanding mechanical and thermomechanical properties, such as biocompatibility, high corrosion, and high work capacity [31,32]. SMA wires can achieve a high stress of about $700 \mathrm{Mpa}$ and strain of $10 \%$ in length. Higher strains can be obtained with special geometries such as helix or zigzag but with lower stresses. Due to their excellent properties, SMAs are widely used in aerospace, mechatronics, biomedicine, bridge construction, automobiles, and daily life [33].
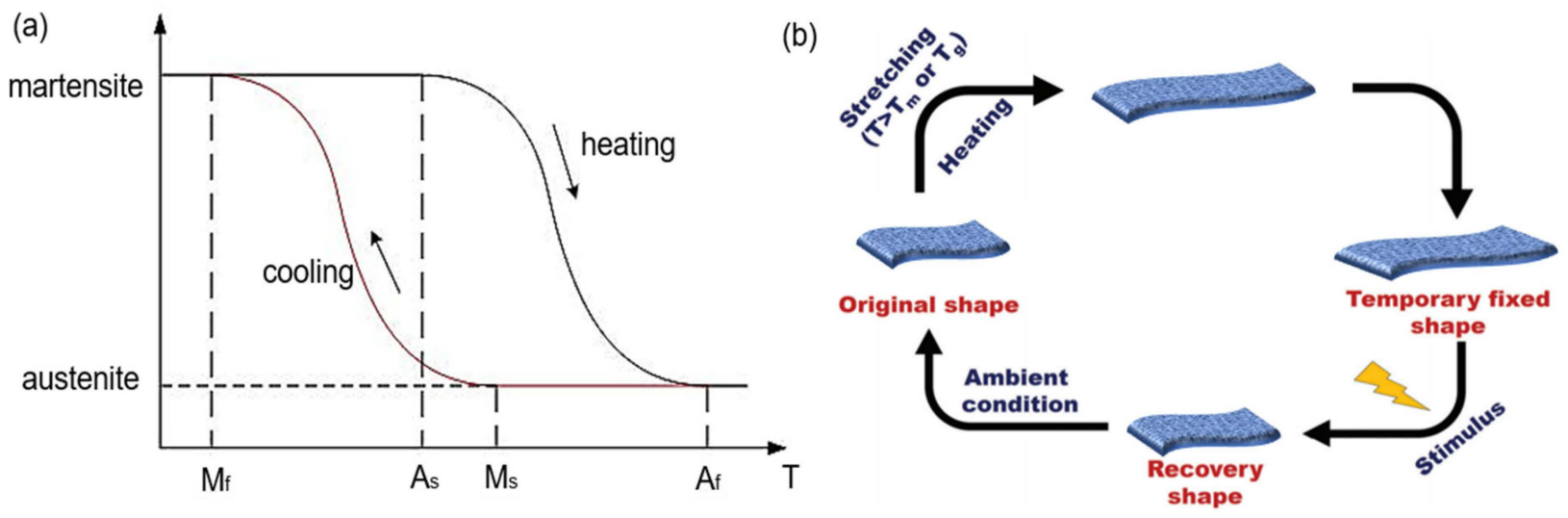

Figure 3. Shape memory principles of SMAs (a) and SMPs (b).

\subsubsection{SMPs}

SMPs are polymeric smart materials that have the ability to return from a deformed state (temporary shape) to their original (permanent) shape in response to an external trigger, such as temperature, an electric or magnetic field, light, or solution [34-36]. As demonstrated for a heat triggered SMP in Figure 1b, the original shape of an SMP is determined after manufacturing by conventional methods such as extrusion, spinning, pressing, etc. The SMP is changed into a temporary shape by processing through heating, deformation, and cooling. The material maintains this temporary shape until it is activated by a predetermined external stimulus. This cycle of programming and recovering can be repeated multiple times. The mechanism behind this phenomenon depends on their molecular network structure, which contains at least two separate phases, namely a fixing phase and a reversible phase [37]. The fixing phase, showing the highest thermal transition, is the temperature that must be exceeded to establish the physical crosslinks responsible for the permanent shape. The fixing phase can be the cross-linked structure, the partial crystalline structure or the glassy state of the polymer, while the reversible phase can be a partial crystalline phase with reversible change of crystallization and melting, or a phase structure with reversible transition between a glass state and rubber state. SMPs can be a single component polymer or a copolymer, a mixture of two components with different softening temperatures but good compatibility. SMPs also cover a wide property-range from stable to biodegradable, from soft to hard, and from elastic to rigid, depending on the structural units that constitute the SMP [38].

\subsubsection{Applications}

SMAs, especially SMA wires, have been widely employed in various soft exoskeletons to replace conventional rigid motors or pneumatic/hydraulic actuators for rehabilitation and assisting patients' daily life including hand [39], elbow [40], wrist [41], ankle [42], etc. For instance, a lower limb-worn, soft wearable robot using an SMA wire has been designed to assist ankle plantar flexion, which can generate a stroke of $3 \mathrm{~cm}$ and an ankle moment of $100 \mathrm{~N} \mathrm{~cm}$ in each ankle during walking (Figure 4a) [42]. A soft muscle glove containing SMA wires has been developed to replicate the functionalities of a human hand. The glove can achieve a functional range of motion of the human hand and can perform a wide range 
of grasp types [43]. A suit-type wearable robot (STWR) containing SMA fabric muscle has been developed to assist the muscular strength of wearers [44]. The STWR can lift barbells weighing $4 \mathrm{~kg}$ to a certain target position and demonstrated a fast response time of less than $1 \mathrm{~s}$ (Figure 4b). A medical rehabilitation exoskeleton using SMA wires as the actuator for the elbow has been proposed for proper patient elbow joint articulation. The proposed exoskeleton is lightweight and has low noise, which improves the medical rehabilitation process and their ability to perform daily activities (Figure 4c) [45].
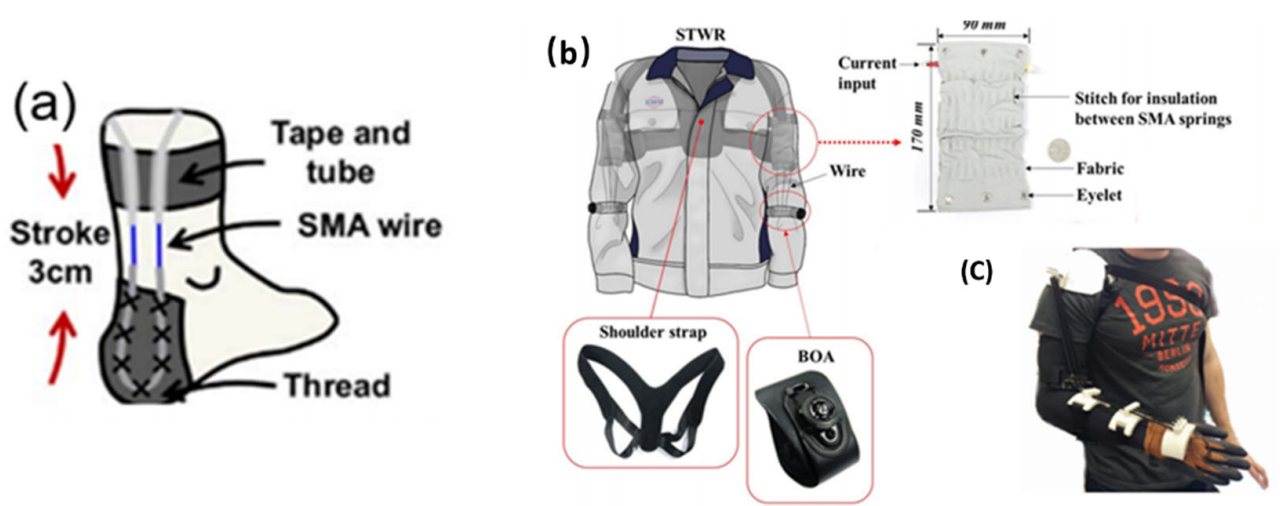

Figure 4. Soft wearable robots using SMA wires. (a) A soft wearable robot using a SMA wire to assist ankle plantar flexion [42]. Copyright 2020, IOP Publishing Ltd. (b) An STWR to assist the muscular strength of wearers [44]. Copyright, 2019, Springer Nature. (c) A medical rehabilitation exoskeleton for proper patient elbow joint articulation [45] Copyright 2017, Dorin Copaci et al.

SMPs have plentiful applications in textiles, such as wrinkle-free fabrics, self-cleaning fabrics, breathable garments, and self-adaptable textiles [6]. Lamination, coating, knitting, and weaving are methods that integrate SMPs into textiles [5]. Thermal responsive SMPs can be applied onto textile fabrics via finishing process. Wrinkle-free, crease retention, or anti-shrinkage textiles can be fabricated by treating SMPs on fabrics. The cotton fabric treated with SMPU showed a good wrinkle-free effect and can return to its original flat shape quickly upon blowing steam over it [46]. Taking the advantages of the change of water vapor permeability of SMPs with temperature makes them capable of regulating the human body temperature [47]. As the body temperature is above the glass transition temperature of SMPs, the molecular free volume of the SMPs significantly increases, which aids the transfer of vapor and heat through perspiration, and vice versa.

\subsubsection{Merits and Demerits}

SMAs have outstanding mechanical and thermomechanical properties, such as biocompatibility, high corrosion, and high work capacity. These allow them to have several commercialized applications in medical tools. However, SMAs exhibit large thermal hysteresis, which makes it hard to control the actuation process. Moreover, the low durability and high material cost (\$200-300/kg) hinder their applications in wearable robots. In contrast to SMAs, SMPs possess many advantages such as light weight, flexibility, high elastic deformation (up to $800 \%$ ), high shape recovery (>90\%), and low recovery temperature, etc. SMPs can be integrated into textiles by various textile processes. Although many textile prototypes and commercial trials have been demonstrated, many issues remain to be resolved. Several difficulties lie in meeting the stringent textile requirements, such as color, dimensional stability, comfort and tactile properties, washability, strength, flexibility, stretchability, as well as compatibility with many other chemical, mechanical, and thermal processing standards, and low-cost production [37]. 


\subsection{Thermal and Hygroscopic Expansion}

\subsubsection{Mechanism}

Thermal or hygroscopic expansion is the tendency of matter to change its volume in response to a change in temperature or moisture content. The macroscopic effect of hygroscopic expansion is similar to that of thermal expansion, but the microscopic causes are very different. Thermal expansion is a result of molecules' vibration and movement when heated, while hygroscopic expansion is caused by hygroscopy, the phenomenon of attracting and holding water molecules via either absorption or adsorption from the ambient environment. The coefficient of thermal expansion $(\alpha \mathrm{T})$ is defined to quantify the magnitude of the volume change in relation to temperature change, which is given by

$$
\alpha_{T}=\frac{1}{V}\left(\frac{\partial V}{\partial T}\right)_{p}
$$

where $V$ is the volumetric expansion, $T$ is the temperature, and $p$ is the pressure held constant during the expansion. In the case of hygroscopic expansion, the temperature $(T)$ in Equation (1) is replaced by the relative humidity $(\varphi)$.

High thermal expansion materials include low-density polyethylene (500 ppm/K) [48], polydimethylsiloxane ( 300 ppm/K) [49], biaxial oriented polypropylene ( $120 \mathrm{ppm} / \mathrm{K})$ [50], etc., while textile cellulose and protein fibers have a high expansion in diameter when wet, such as cotton (7-20\%), jute (20-21\%), wool (14-17\%), and silk (16-19\%) [51]. These materials' expansion behavior has been utilized to fabricate various tensile, bending, and torsional actuators for wearable applications, as shown in Figure 5.

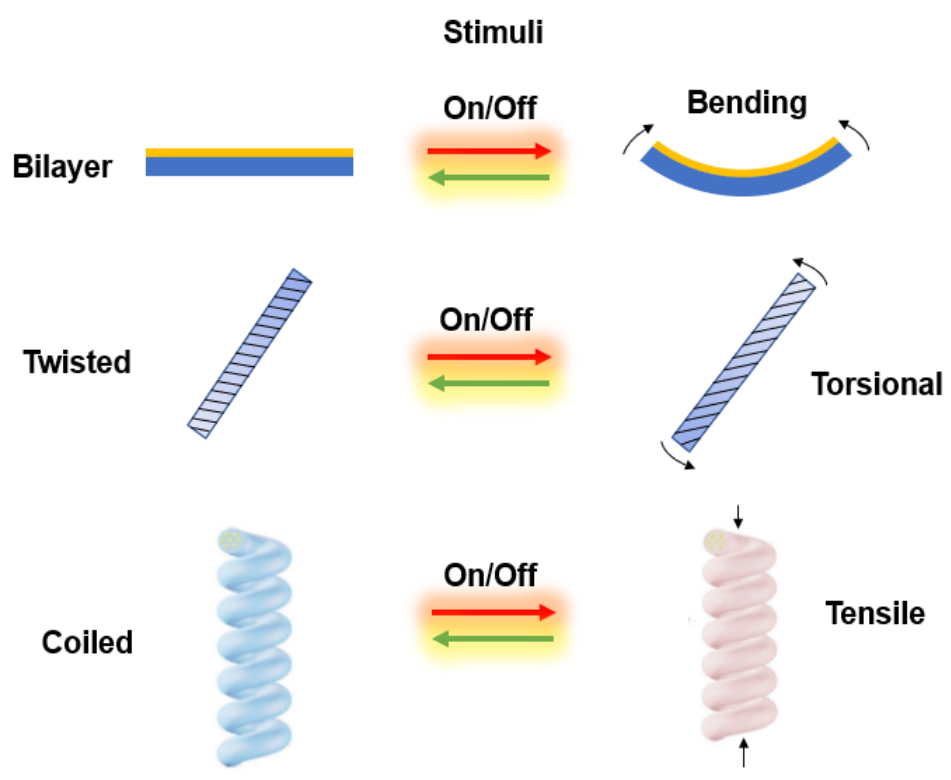

Figure 5. A schematic diagram of heat or moisture induced actuators.

\subsubsection{Structure}

Bimorph structure is a widely adopted strategy to generate bending motion via asymmetric deformation of the two layers, an active layer that contracts or expands by an external stimulation and a passive layer that remains intact. The interfacial stress generated between the two layers due to the volume mismatch leads to bending deformations. There are many examples of bending actuators in the film form, such as LDPE/PVC film [48], poly(vinyl alcohol-co-ethylene) (EVOH)/cellulose film [52]. Alternatively, asymmetric exposure of water vapors or heat to the thin film of moisture or heat responsive materials can also achieve the bending motions, but the bending performance is thickness sensitive. Examples includes microfibrillated cellulose film [53] and nylon beam coated with thermally conductive graphene flakes [54]. Some bimorph fibers have also been developed. 
Cyclic olefin copolymer elastomer/HDPE fiber was developed by using a fiber-drawing technique, and can lift more than 650 times its own weight at a low temperature [55]. A moisture trigged acetate-based conjugate fiber $\left(\operatorname{Ventcool}^{\mathrm{TM}}\right)$ was created by the Kaiteki company to automatically adjust ventilation of clothing [56].

Torsional fiber actuators are realized by twisting moisture and heat responsive fibers to form a yarn like structure with free-standing torque balanced status. The yarn torque or torsional movement is generated by anisotropic swelling of fibers in the radial direction when exposed to a stimulus. When the stimulus is off, the deswelling of fibers causes the actuator to rotate in the opposite direction and finally returns to the balanced status. Accompanying the torsional movement, the twisted yarn or fiber actuators also show a tensile expansion and contraction behavior due to the twist contraction effect. For example, degummed silk fibers were twisted and folded into torsional silk muscles that provided a reversible torsional stroke of $547^{\circ} \mathrm{mm}^{-1}$, a maximum rotary speed of $975 \mathrm{rpm}$, and a peak torque of $0.063 \mathrm{Nm} / \mathrm{kg}$ [57]. Twisted graphene oxide (GO) fiber demonstrated remarkable performance as a reversible rotary motor with a torsional stroke $588^{\circ} \mathrm{mm}^{-1}$, a rotary speed of up to $5190 \mathrm{rpm}$, a tensile expansion of $4.7 \%$, and a peak power output of $71.9 \mathrm{~W} / \mathrm{kg}$. The moisture-triggered electric generator based on GO fibers produced an open-circuit voltage of up to $1 \mathrm{mV}$, and a short-circuit current of up to $40 \mu \mathrm{A}$ [58]. Hydrophobic carbon nanotube (CNT) twisted yarns offered a maximal torsional moment of $0.4 \mathrm{Nm} / \mathrm{kg}$, close to the commercial electric motor (the Aerotech model 1410-01motor) in response to water and moisture after oxygen plasma treatment [59]. Other fiber materials include bamboo [60], cotton [61], lotus [62], chitosan [63], etc. The performance of several fiber-based torsional actuators is summarized in Table 1.

Table 1. Performance of fiber-based torsional actuators.

\begin{tabular}{|c|c|c|c|c|c|c|}
\hline Material & Stimulus & $\begin{array}{l}\text { Amplitude of } \\
\text { Stimulus }\end{array}$ & Stroke $\left({ }^{\circ} \mathrm{mm}^{-1}\right)$ & $\begin{array}{c}\text { Rotary Speed } \\
\text { (rpm) }\end{array}$ & $\begin{array}{l}\text { Peak Torque } \\
\text { (Nm/kg) }\end{array}$ & Reference \\
\hline GO & moisture & $85 \% \mathrm{RH}$ & 588 & 5190 & 0.082 & [64] \\
\hline CNT & moisture & water droplet & 62.16 & - & 0.4 & [59] \\
\hline Bamboo & moisture & wet & 64.4 & - & - & [60] \\
\hline Cotton & moisture & wet & 42.55 & 720 & - & [61] \\
\hline Chitosan & moisture & wet & 1155 & - & - & [63] \\
\hline Silk & moisture & $60 \% \mathrm{RH}$ & 547 & 975 & 0.063 & [57] \\
\hline Lotus & moisture & $60 \% \mathrm{RH}$ & 200 & 200 & 0.488 & [62] \\
\hline
\end{tabular}

Fiber-based tensile actuators are achieved by twisting and coiling the fibers to form a spring-like structure. The actuating principle lies in anisotropic swelling of the fibers in the radial direction, causing the yarn to untwist and in turn the coil to change its writhe, which pulls the adjacent coils close to each other, shortening the coil. When used as a tensile actuator, the cylindrical yarn coil should be torsionally tethered such that the two ends can slide but not be allowed to rotate, which prevents the yarn from untwisting. This concept was first proposed by Harins et al. [65] in 2014, in which low-cost high-strength nylon fibers, used as fishing line or sewing thread, have demonstrated a high stroke of $34 \%$ for a temperature variation of $\sim 220^{\circ} \mathrm{C}$. Likely, composite yarns made of polyimide and PDMS have achieved a tensile actuation of $20.7 \%$ and a competitive specific work of $158.9 \mathrm{~J} / \mathrm{kg}$, four times that of natural muscle [64]. Surfactant-treated wool yarn coils generated a contraction stroke up to $38 \%$ and a maximum work capacity of $194 \mathrm{~J} / \mathrm{kg}$ [66]. Viscose fiber artificial muscles demonstrated a $35 \%$ contraction and a maximum work capacity of $90.4 \mathrm{~J} / \mathrm{kg}$ [67]. Degummed silk fibers were twisted and wrapped around a mandrel to form tensile actuators that provided a maximum $70 \%$ contraction and peak work capacity up to $73 \mathrm{~J} / \mathrm{kg}$ [57]. Other fiber materials include carbon fiber (CF)/PDMS [68], lotus [62], bamboo [60], etc. The performance of several fiber-based tensile actuators is summarized in Table 2. 
Table 2. Performance of fiber-based tensile actuators.

\begin{tabular}{|c|c|c|c|c|c|c|}
\hline Material & Stimulus & $\begin{array}{c}\text { Amplitude of } \\
\text { Stimulus }\end{array}$ & Strain (\%) & Stress (Mpa) & $\begin{array}{l}\text { Work Density } \\
(\mathrm{J} / \mathrm{kg})\end{array}$ & Reference \\
\hline Nylon 6,6 & heat & $240^{\circ} \mathrm{C}$ & 34 & 22 & 2480 & [65] \\
\hline Polyethylene & heat & $130^{\circ} \mathrm{C}$ & 16 & 16 & 2630 & [65] \\
\hline PI/PDMS & heat & $210^{\circ} \mathrm{C}$ & 20.7 & 1.2 & 158.9 & [64] \\
\hline CF/PDMS & heat & $200^{\circ} \mathrm{C}$ & 25 & 60 & 758 & [68] \\
\hline Bamboo & moisture & $90 \% \mathrm{RH}$ & 50 & 0.75 & 1.08 & [60] \\
\hline Wool & moisture & wet & 38 & 2.6 & 194 & [66] \\
\hline Viscose & moisture & wet & 35 & 0.28 & 90.4 & {$[67]$} \\
\hline Silk & moisture & $60 \% \mathrm{RH}$ & 70 & 3.2 & 73 & [57] \\
\hline Lotus & moisture & $70 \% \mathrm{RH}$ & 38 & 13 & 450 & [62] \\
\hline
\end{tabular}

\subsubsection{Applications}

There are many applications of moisture or heat responsive materials for smart textiles, which dynamically change the structure or pore size of clothing for enhanced personal thermal management [69]. For instance, two kinds of moisture responsive bendable smart clothing were designed based on the successful application of the Nafion film from DuPont that can reversibly adapt their thermal insulation functionality [70]. The first design is pre-cut flaps, which open to produce pores in Nafion sheets when humidity increases, allowing air flow and reducing both the humidity level and the apparent temperature (Figure 6a). The second design is thickness adjustable clothes by inserting the bent Nafion films between two fabrics. When the humidity increases, the films become thinner, thus reducing the gap between the two fabrics to reduce the thermal insulation (Figure 6b). Knitted fabrics made of CNTs coated triacetate-cellulose bimorph fibers effectively shifted the infrared radiation (IR) by more than $35 \%$ as the relative humidity of the underlying skin changed [71]. When hot and wet, the multiple metafibers move close to each other, leading to resonant electromagnetic coupling that modulates the IR emissivity to spectrally overlap with that of the human body and enhance radiative cooling effect. A woven textile from silk fiber muscles demonstrated excellent comfort and drapability. The sleeves, made by weaving coiled silk muscle fibers in the warp direction and untwisted fibers in the weft direction, shrink in the warp direction when humidity increases, and then expand when humidity decreases [57]. This moisture-responsive textile, which can change macroshape or microstructure, is promising to be very effective for moisture and thermal management to increase comfort between skin and fabric (Figure 6c). In addition to hygroscopic polymer materials, living cells have been engineered to design biohybrid wearables [72]. A bilayerstructured biohybrid film was proposed by depositing genetically tractable microbes on a humidity-inert material to form a heterogeneous multilayered structure, which can reversibly change shape within a few seconds in response to environmental humidity gradients (Figure 6d).

\subsubsection{Merits and Limitations}

There are some advantages and limitations for the thermal or hygroscopic driven actuators. Commercially available fibers such as nylon, PE, and bamboo are inexpensive and they can be easily converted into torsional and tensile actuators. In terms of the structure, although several film-based actuators have been demonstrated, they are difficult to be developed into a textile structure for wearables. Fiber-based actuators are more promising and have demonstrated their capabilities to be used for personal thermal regulation. Moreover, thermal responsive actuators usually need a high temperature for desired stress and strain, causing possible discomfort and injuries for humans, and thus hinders their applications in smart textiles. In addition, the energy efficiency of heat driven actuators is very low $(<1 \%)$, and the cycling rate is low due to the poor heat diffusion and dissipation, especially during the cooling process, so they take a longer time for heating 
and cooling [2]. For moisture responsive actuators, their durability and performance need to be further explored.

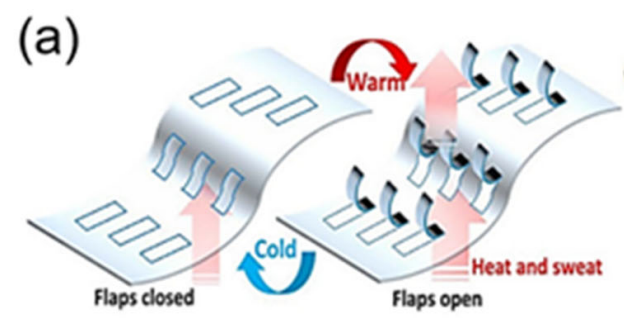

(a)

(c)

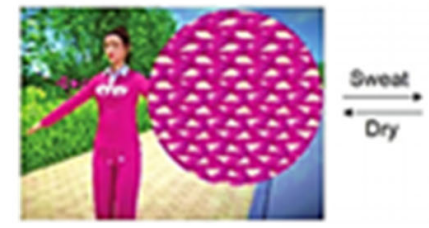

(b)

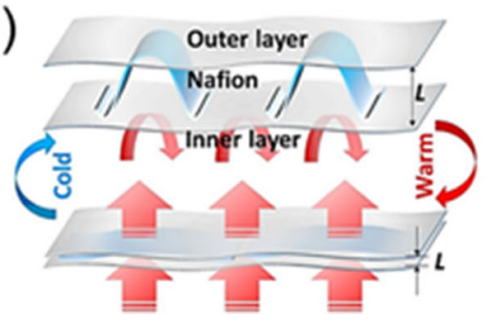

(d)

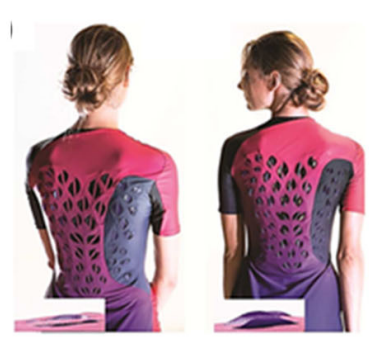

Figure 6. Moisture and heat responsive smart textiles. (a) Nafion sheet schematics with openable flaps mimicking thermo-adaptive functionality of human skin [70]. Copyright 2017, Springer Nature. (b) The schematic of the thickness reversible structure using nafion as a thermally adaptive interlayer [70]. Copyright 2017, Springer Nature. (c) Schematic diagram of moisture sensitive clothing changing sleeve and pant length before and after exercise [57] Copyright 2017, Wiley-VCH. (d) Running suit prototype with ventilation flaps based on the moisture sensitive biohybrid two-layer film [72]. Copyright 2017, the authors, published by AAAS.

\subsection{Dielectric Elastomer Actuators}

\subsubsection{Mechanism}

Dielectric elastomer actuators (DEAs) are electronic electroactive polymers that enable electromechanical transduction at effective electrical fields, transferring electrical energy into mechanical work $[7,73]$. The working principle of a DEA is based on the basic configuration that two compliant electrodes are coated on each side of a thin polymer film to form a deformable capacitor (Figure 7). According to the elastic electrostatic model first established by Pelrine et al. [74,75], due to the inherent volume incompressibility, when an electrical field is applied perpendicularly to the plane of the two electrodes, two mechanisms are generally induced: the attractive electrostatic forces among opposite charges on each electrode cause the polymer film to compress in thickness and the repulsive electrostatic forces among like charges over the same electrode render further expansion in area, reducing the electrical energy [7,74]. For an ideal elastic model, electrostatic energy is equally converted to mechanical energy through lateral and transverse displacement [74]. The capacitance $(C)$ of the dielectric film is

$$
C=\varepsilon_{0} \varepsilon A / z
$$

and thus the stored electrostatic energy $(U)$ is given by:

$$
U=0.5 \frac{Q^{2}}{C}=0.5 \frac{Q^{2} z}{\varepsilon_{0} \varepsilon A}
$$

where $Q$ is the fixed charge on the electrodes, $A$ is the area of the electrode, $z$ is the thickness of the $\mathrm{DE}$ film, $\varepsilon_{0}$ is the free-space permittivity, and $\varepsilon$ is the relative permittivity (dielectric constant) of the DE material. 


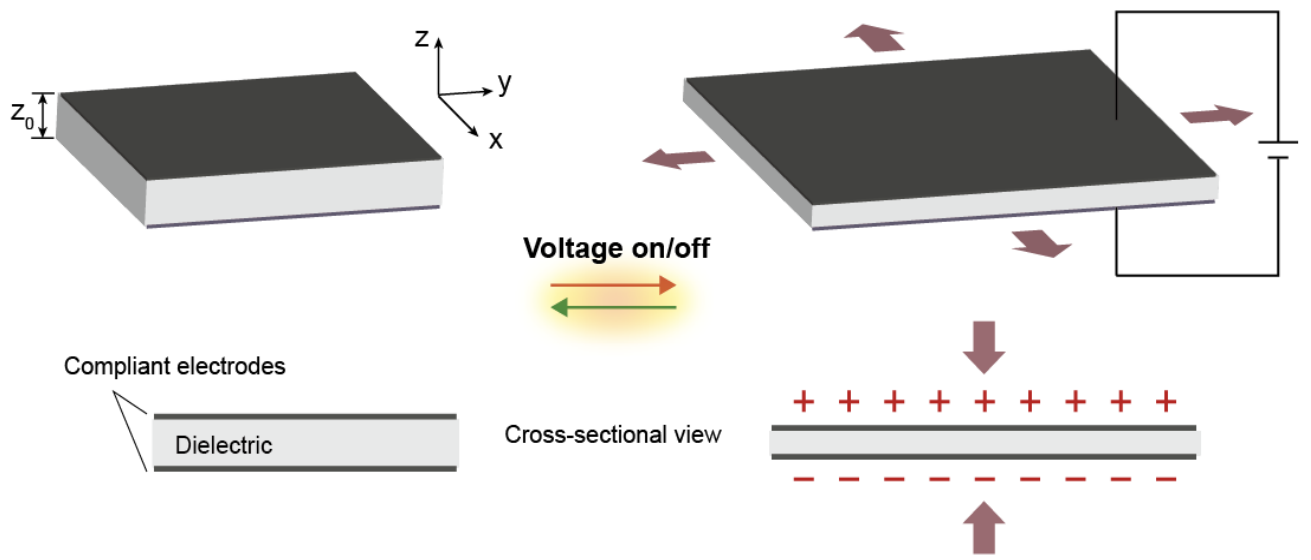

Figure 7. Schematic diagram of the operational principle of a DEA.

The electrostriction effect of a DEA upon the application of a proper electric field is believed to be caused by the formation of the effective compressive pressure $P$, also known as the Maxwell stress, which is defined as the electrostatic energy change per unit thickness displacement per unit area [74]:

$$
p=\varepsilon_{0} \varepsilon E^{2}=\varepsilon_{0} \varepsilon\left(\frac{V}{z}\right)^{2}
$$

Given that $A z=$ constant, the effective stress $(p)$ can be obtained:

$$
p=\varepsilon_{0} \varepsilon E^{2}=\varepsilon_{0} \varepsilon\left(\frac{V}{z}\right)^{2}
$$

where $E$ is the applied electric field, and $V$ is the applied voltage.

For low strains $(<10 \%)$, the actuated strain in the thickness direction $\left(s_{z}\right)$ can be defined as below according to the Hooke's Law in compression [3,5]:

$$
s_{z}=-\frac{p}{Y}=-\frac{\varepsilon_{0} \varepsilon\left(\frac{V}{z}\right)^{2}}{Y}
$$

where $Y$ is the elastic modulus of the dielectric elastomer.

The above equations are built on the assumption of linearly elastic behavior of the DEA under relatively small strains. However, polymers are generally nonlinear materials and more complex constitutive relationship need to be taken into account. For example, the elastic modulus essentially depends on the strain (i.e., $Y=Y(s)$ ) for nonlinear materials. In addition, as large in-plane extension is exhibited, the actual thickness under actuation can be described in relation to the original value $\left(z_{0}\right)$ as:

$$
z=z_{0}\left(1+s_{z}\right)
$$

and the constancy of volume can be expressed as

$$
\left(1+s_{x}\right)\left(1+s_{y}\right)\left(1+s_{z}\right)=1
$$

If the in-plane deformation is symmetric, i.e., $s_{x}=s_{y}=s_{x y}$, more accurate thickness strain can be expressed by [76]:

$$
s_{z}=\left(1+s_{k}\right)^{-2}-1
$$

As described in Equations (5) and (6), the dielectric constant $(\varepsilon)$, elastic modulus $(Y)$, electric field $(E)$ /applied voltage $(V)$ and film thickness $(z)$ proportional to the Maxwell stress and thickness strain are key parameters to consider in assessing the actuation perfor- 
mance of DEAs. Normally high voltage $(>1 \mathrm{kV})$ or electric fields $(\sim 100 \mathrm{MV} / \mathrm{m})$ are needed for better actuation output and allow for higher energy efficiency as they lead to smaller current, yet they are often considered disadvantageous for practical applications [73,76]. Hence, key pathways of countering the common limitation of high driving voltage and improving the electrical stimulated actuation performance of a DEA membrane consist in: (1) decreasing film thickness, (2) increasing DE dielectric constant, and (3) reducing DE intrinsic stiffness and viscoelastic loss. Common approaches of enhancing electromechanical responses include physically pre-straining (pre-stretching), chemically modifying the elastomer to tune its modulus/stiffness and electromechanical properties through composites, polymer blends and copolymers, and employ highly compliant electrodes that have high conductivity, little/no stiffening effect upon large strains and the ability of self-clearing such as carbon particle-based electrodes [77].

Since the early investigation of DEAs, acrylic and silicone elastomers have stood out and been widely studied due to their superior overall actuation performance compared to other commonly reported materials such as polyurethane, polyisoprene and fluoroelastomers $[75,76]$. General comparison between the properties of the two main elastomeric matrices: acrylics (mixtures of aliphatic acrylate) and silicones (polysiloxanes, e.g., most commonly used polydimethylsiloxane (PDMS)), is summarized in Table 3.

Table 3. Comparison between acrylic and silicone elastomers [77-79].

\begin{tabular}{|c|c|c|c|c|c|c|}
\hline Material & Viscoelasticity & $\begin{array}{l}\text { Dielectric Constant } \\
\text { (at } 1 \mathrm{~Hz} \text { ) }\end{array}$ & $\begin{array}{l}\text { Actuated Strain } \\
\text { (Prestrained) }\end{array}$ & $\begin{array}{l}\text { Adhesion } \\
\text { Property }\end{array}$ & $\begin{array}{l}\text { Thermal } \\
\text { Stability }\end{array}$ & $\begin{array}{l}\text { Moisture } \\
\text { Property }\end{array}$ \\
\hline Acrylics & $\begin{array}{l}\text { High, resulting in } \\
\text { long-term relaxation } \\
\text { and slower } \\
\text { response }\end{array}$ & $\begin{array}{c}\text { High } \\
(4.5-4.8)\end{array}$ & $\begin{array}{c}\text { High } \\
(\sim 380 \% \text {, area })\end{array}$ & Good & $\begin{array}{c}\text { Low } \\
\left(-10 \sim 80^{\circ} \mathrm{C}\right)\end{array}$ & $\begin{array}{l}\text { Sensitive to } \\
\text { humidity }\end{array}$ \\
\hline Silicones & $\begin{array}{c}\text { Low, } \\
\text { due to flexible } \\
\text { backbone (-Si-O-) }\end{array}$ & $\begin{array}{c}\text { Low } \\
(2.5-3)\end{array}$ & $\begin{array}{c}\text { Modest } \\
(\sim 120 \% \text {, linear })\end{array}$ & $\begin{array}{c}\text { Poor } \\
\text { (low surface } \\
\text { energy) }\end{array}$ & $\begin{array}{c}\text { High } \\
\left(-65 \sim 240{ }^{\circ} \mathrm{C}\right)\end{array}$ & $\begin{array}{l}\text { Low rate of mois- } \\
\text { tureabsorption }\end{array}$ \\
\hline
\end{tabular}

\subsubsection{Structure}

Configurational designs of DEAs differ with applications and generally manipulate the basic operational mechanism to transduce electrical power into mechanical work to achieve amplified performance of in-/out-of-plane deformation such as contraction, expansion and bending. Common structures derived from the fundamental membrane prototype include multi-stack [80], interdigitated [81], and twisted [82] contractile devices; rolled [83], cone-shaped [84], and diaphragm [4]. DEAs exhibit linear or areal expansion. Multi-stack architecture is an effective approach to augmenting the effect of the Maxwell stress and generating amplified contractile actuation and load-bearing capacity (Figure 8a). Twisted actuators are developed from spiral cylindrical stacked DEAs to enhance their operational stability and ensure inherent flexibility, the actuated strain of which depends on the helix angle (Figure 8b) [82]. In contrast, cone-shaped (Figure 9a) and rolled (Figure 9b) DEAs utilize areal expansion to produce axial extension and amplified forces. Tunable two-cone actuators with proper voltage excitation modes enable the control of multi-directional and rotational actuation [85]. Zhao et al. [83] developed rolled multilayer DEAs that are able to produce a force of $1 \mathrm{~N}$ and strain of $10 \%$ at small driving voltages lower than $1 \mathrm{kV}$. The out of plane protrusion of diaphragm DEAs is triggered by two working modes: one is based on a physical support or boundary constraint and the other requires an external pressure for amplified actuation [86], which has found its applications in optical lenses [87], haptic interfaces [4] and braille displays [88], etc. Additionally, bendable DEAs with functional elements such as laminated passive layers in the form of unimorphs or bimorphs are also commonly investigated (Figure 10a) [89,90]. Bending motion has also been realized by multi-degree-of-freedom spring roll configuration with patterned electrodes that are circumferentially aligned (Figure 10b) [91]. The actuation performance of several DEAs with common structures is shown in Table 4. 


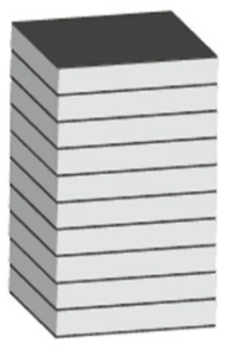

(a)
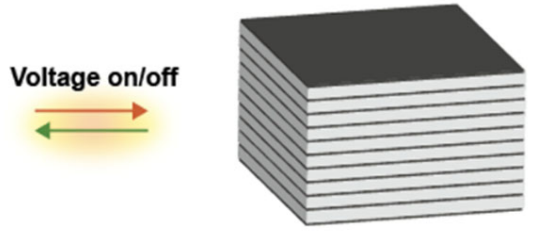

(b)
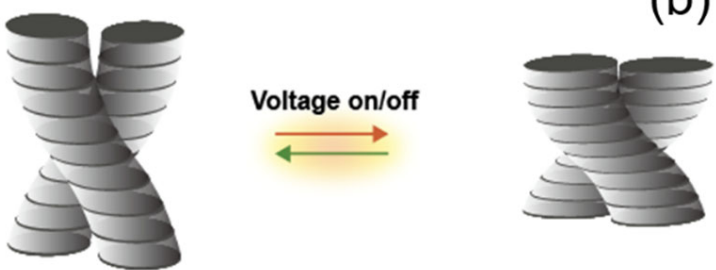

Figure 8. Schematics of contractile DEAs: (a) multi-stack structure; (b) twisted structure.

(a)

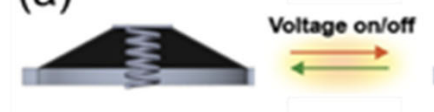

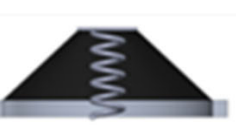

(b)

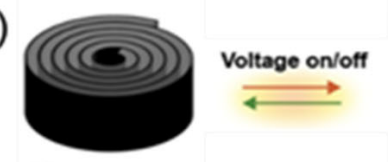

Figure 9. Schematics of expansion DEAs. (a) Cone-shape structure [78]. (b) Rolled structure [78] Reproduced under the terms and conditions of the Creative Commons Attribution (CC BY) license (http://creativecommons.org/licenses/by/4.0/). Copyright 2020, The authors. Licensee MDPI, Basel.

(a)
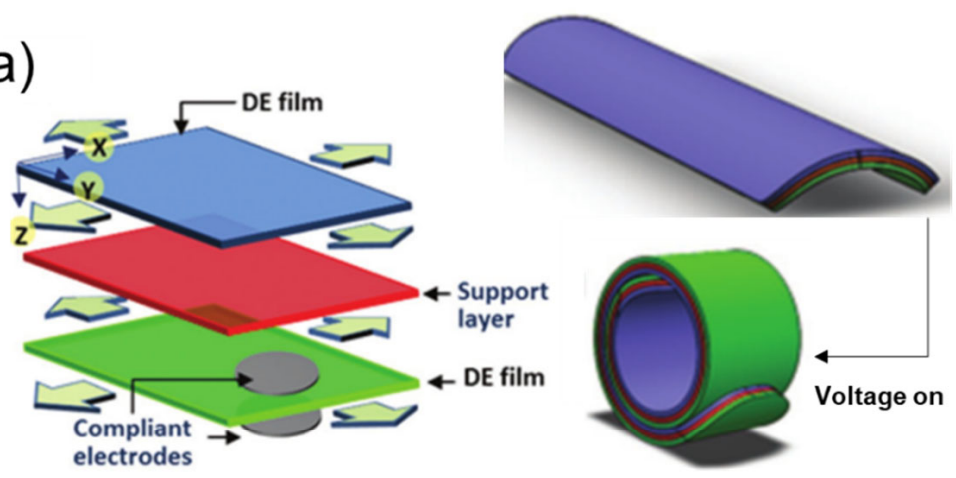

(b)
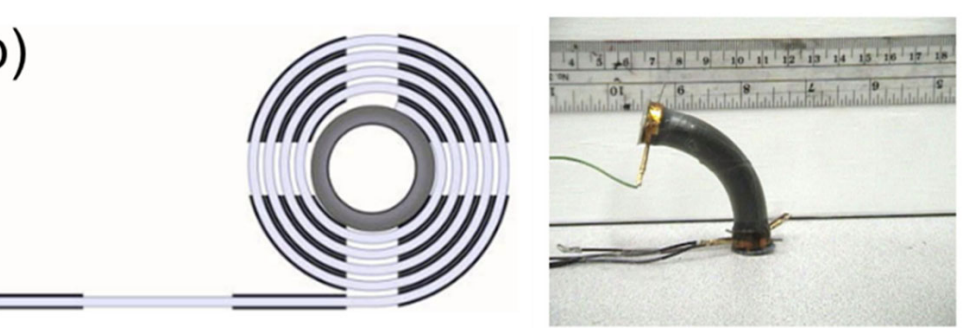

Figure 10. Schematics of bending DEAs: (a) multilayer bistable structure with bending features [90]. Copyright 2018, Wiley-VCH; (b) 2-degree-of-freedom spring roll structure and a prototype [91]. Copyright 2004, IOP Publishing. 
Table 4. Performance of dielectric elastomer actuators with common structures.

\begin{tabular}{|c|c|c|c|c|c|c|}
\hline Structure & Multi-Stack & Twisted & Rolled & Cone & $\begin{array}{l}\text { Buckling } \\
\text { Diaphragm }\end{array}$ & $\begin{array}{l}\text { Bending } \\
\text { Unimorph }\end{array}$ \\
\hline DE material & $\begin{array}{c}\text { Acrylic } \\
\text { (VHB 4910, } \\
\text { IPN post-processed) }\end{array}$ & $\begin{array}{c}\text { Silicone } \\
\text { (Wacker Elas } \\
\text { tosil P7670) }\end{array}$ & $\begin{array}{c}\text { Silicone (Sylgard } \\
184 \text { and Ecoflex } \\
0030)\end{array}$ & $\begin{array}{c}\text { Silicone (Wacker } \\
\text { Elas } \\
\text { Tosil) }\end{array}$ & PDMS & $\begin{array}{c}\text { Formulated } \\
\text { acrylic } \\
\text { (oligomer: } \\
\text { CN9014) }\end{array}$ \\
\hline Electrode material & $\begin{array}{l}\text { Silicone/ } \\
\text { carbon-black } \\
\text { mixture }\end{array}$ & $\begin{array}{l}\text { Carbon black, } \\
\text { graphite and } \\
\text { ethanol }\end{array}$ & $\begin{array}{l}\text { Single-walled } \\
\text { carbon nanotubes } \\
\text { (SWCNTs) }\end{array}$ & Carbon black & $\begin{array}{c}\text { Silver } \\
\text { nanowires } \\
\text { (AgNWs) }\end{array}$ & SWCNTs \\
\hline Prestrain & $200 \%$ areal & None & None & $10 \%$ areal & None & None \\
\hline Voltage $(\mathrm{kV})$ & 4.2 & 6.5 & 1 & 4.5 & 4 & 4 \\
\hline Specific power $(\mathrm{W} / \mathrm{kg})$ & - & 13.7 & 55 & - & - & $19.5 \pm 1.01$ \\
\hline Energy density $(\mathrm{J} / \mathrm{kg})$ & 12.9 & - & 0.275 & - & - & $1.95 \pm 0.10$ \\
\hline $\begin{array}{l}\text { Strain/displacement } \\
\text { (without load) }\end{array}$ & $30 \%$ & $5.2 \%$ & $10 \%$ & $2.3 \%$ & $650 \mu \mathrm{m}$ & $16 \mathrm{~mm}$ \\
\hline $\begin{array}{l}\text { Blocking/output force } \\
(\mathrm{mN})\end{array}$ & - & - & 1000 & 185 & 255 & $12.5 \pm 0.9$ \\
\hline Reference & [80] & [92] & [83] & [84] & [4] & [89] \\
\hline
\end{tabular}

PDMS-based DEAs with a pyramidal microstructure allowed for the tunability of modulus and dielectric properties and achieved enhanced actuation performance (pressure up to $25 \mathrm{kPa}$ and vibrotactile cycles up to 250,000) [93]. A novel design of a dielectric liquid actuator utilized hydraulic-coupled electrostatic effect to amplify electrical simulated actuation and enable peak performance surpassing that of natural muscle (specific power of $614 \mathrm{~W} / \mathrm{kg}$ and load capacity of $700 \mathrm{~g}$ for a 2-unit planar hydraulically amplified selfhealing electrostatic (HASEL) actuator) [94]. Inspired by the HASEL actuators, a recent effort incorporated the mechanism into origami and created programmable shape-altering interfaces with three dimensional folding features [94].

DEAs with bistable structures have also been developed for the purpose of shape transformation between two equilibrium states. Shao et al. [90] developed disk and tapespring bistable actuators with a support layer sandwiched by two DE layers based on the bioinspired snap-through mechanism. A pair of electrodes on each DE layer and the control of a dual power supply enable the disk DEAs to shift the curvature bidirectionally, while with two electrodes on one DE layer, the tape-spring DEAs, snap upon electrical stimulation mimicking a chameleon's tongue [90]. Another established bistable mechanism lies within the bistable electroactive polymers (BSEPs). The actuated shape can be maintained by decreasing the temperature below the glass transition temperature of the DE after electrical excitation, saving the need for a constant power supply and thus energy consumption and increasing stiffness for adaptive applications, the rubbery-to-rigid transition of which is recoverable and repeatable [95].

\subsubsection{Applications}

The properties of DEAs fit into a wide realm of applications owing to their versatility and outstanding actuation performance. For wearable assistance in particular, research has mainly explored communication and rehabilitation. As haptic feedback is an important part of electronic textiles and wearable technologies, integrating DE tactile actuators into wearable systems through haptic sensation has been a rising field of interest attributed to material softness, small size, ease of fabrication, and adaptability compared to traditional rigid motors with fixed frequencies [96]. A crucial factor for effective sensing of haptic cues is skin perceptibility, which means the output force and resonance frequency should reach perceivable levels and depends on both human and device factors, such as placement on bodies and material stiffness $[96,97]$. For example, typically fingertips are ideal positions on tactile devices due to their higher sensitivity than other parts such as arms, and are usually susceptible to a force threshold around $30 \mathrm{mN}$ depending on the fingers [98]. Hence, one of the main goals in the current development of DEA haptic wearable interfaces is to generate large force and displacement outputs at such a small (millimeter) scale [96,99]. Meanwhile, 
as human contact is involved, the design of wearable haptic interfaces using DEAs needs to account for various aspects such as compactness, weight, comfort, safety, etc.

Most current designs of wearable haptics have leveraged the out-of-plane deformation of diaphragm/membrane $[96,100]$ and linear displacement of rolled multilayer [101] configurations, as well as the hydraulic amplification with liquid coupling effect [99]. Multilayered PDMS membranes coated by AgNWs electrodes with a perforated polymeric frame support were able to generate an output force up to $255 \mathrm{mN}$ and a protrusive displacement of $650 \mu \mathrm{m}$ [14]. More recently, hydraulically amplified taxel (HAXEL) actuators designed with four quadrants consisting of P(VDF-TrFE-CTFE) liquid dielectric and segmented aluminum electrodes were able to simulate directional motions and produce forces over $300 \mathrm{mN}$ and a vertical displacement of $500 \mu \mathrm{m}$ (Figure 11) [99]. Prototype demonstrations have integrated the haptic functions into wearables such as armbands $[4,99,101]$, rubber gloves [4] and fingertip devices (Figure 12) [96,100] for potential applications of human-machine interaction and virtual/augmented reality. Untethered wearable tactile actuators were realized by on-board battery integration into compact feel-through lowvoltage $(<500 \mathrm{~V})$ DEAs (FT-DEAs) with a thickness of only $18 \mu \mathrm{m}$ and a wide vibrotactile frequency range of $1-500 \mathrm{~Hz}$, and the fingertip prototype with incorporated photodetector was demonstrated to be applicable in assisting text-reading for people with vision impairment (Figure 12) [96].

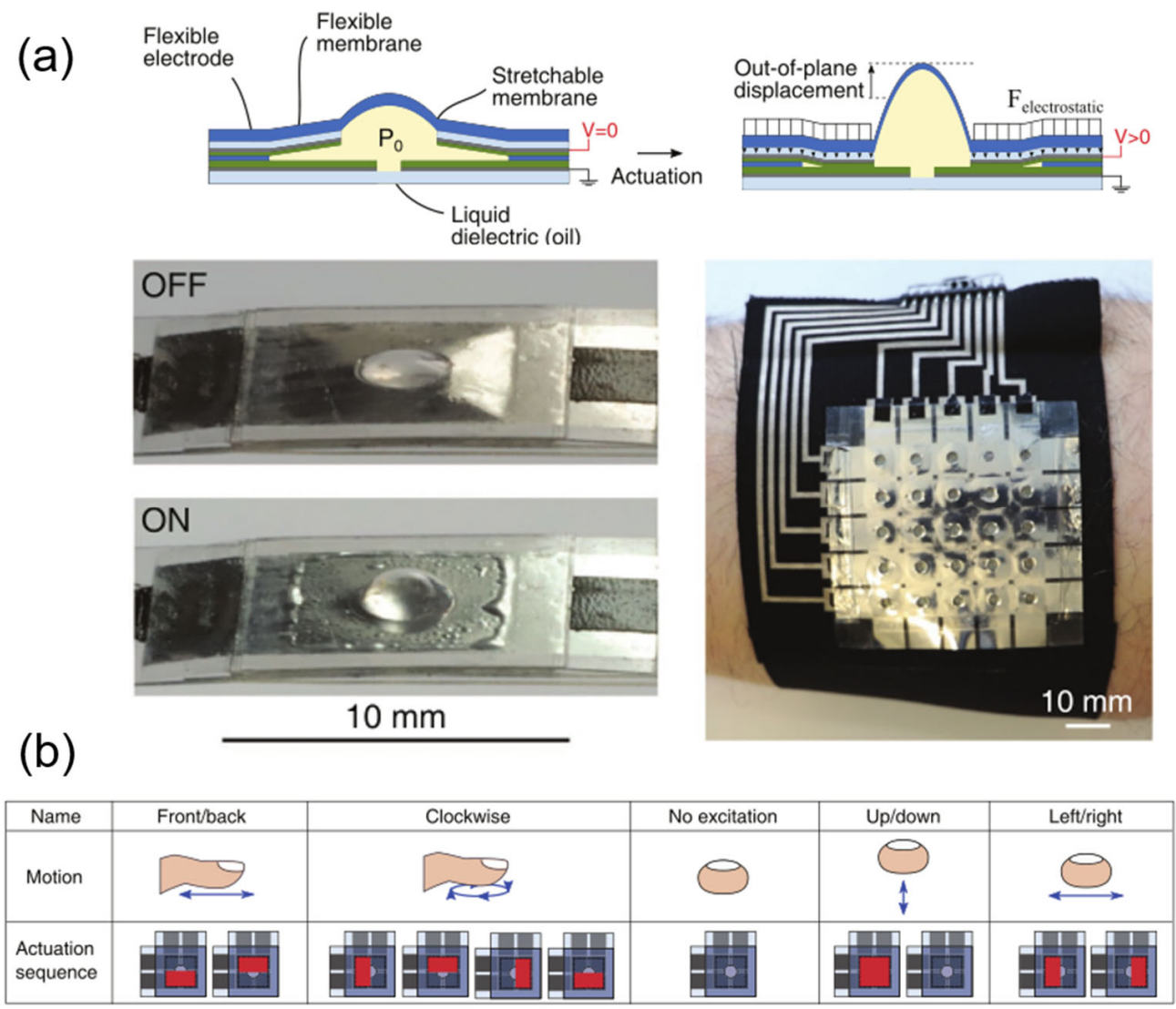

Figure 11. Schematics and prototypes of wearable HAXEL actuators. (a) Schematic diagrams of a HAXEL actuator and an armband prototype of 5x5 array HAXELs [99]. Copyright 2020, Wiley-VCH. (b) Haptic testing modes with various directional motions based on a four-quadrant HAXEL [99]. Copyright 2020, Wiley-VCH. 

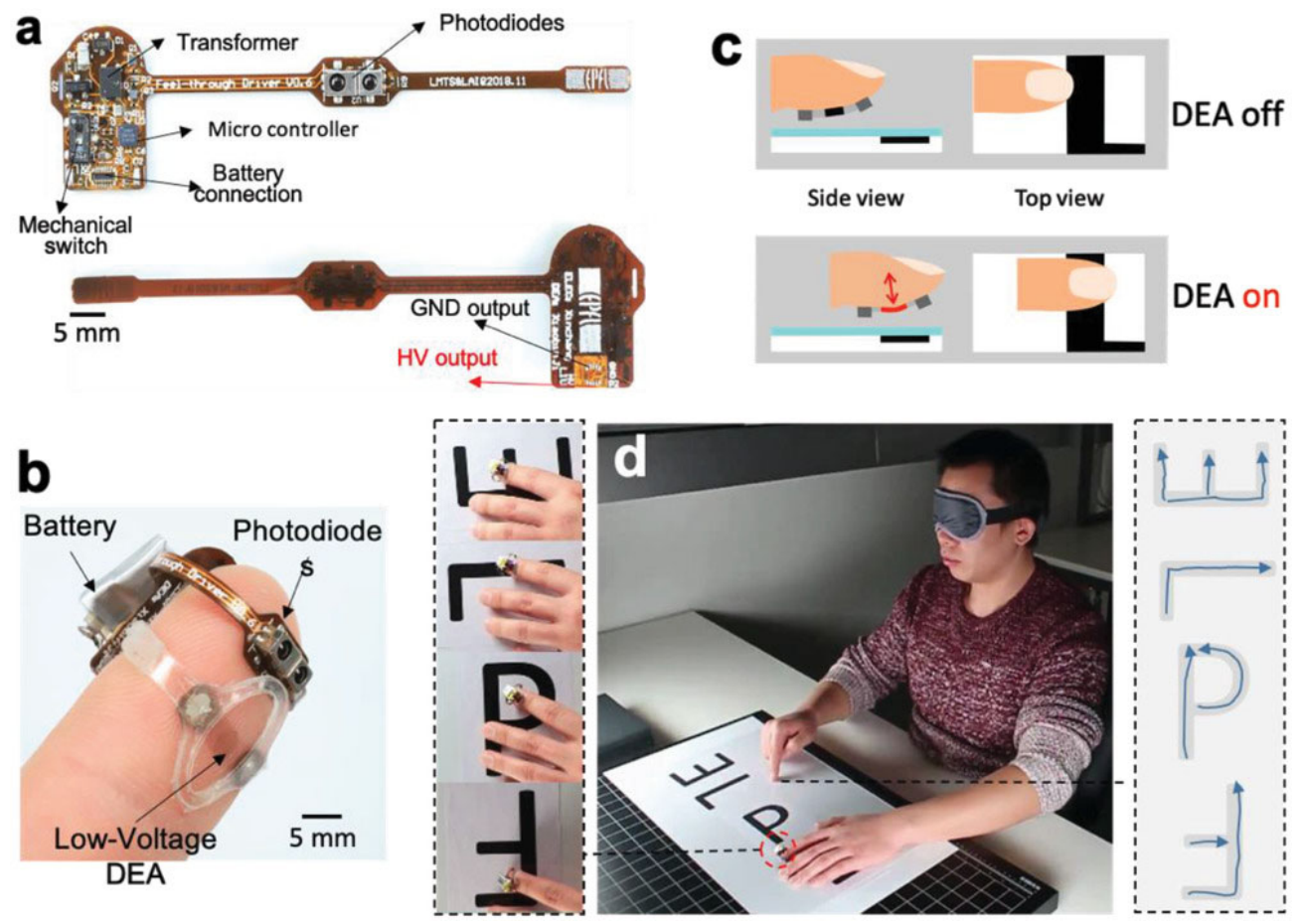

Figure 12. Schematics and prototypes of wearable fingertip tactile DEAs. (a) The wireless driver circuit. (b) Untethered "feel-through" haptic device on a fingertip. (c) Operating principle of Untethered FT-DEA. (d) The blindfolded user correctly identifies randomly rotated and placed letters E, P, F, and L [96]. Copyright 2020, Wiley-VCH.

Apart from the aforementioned properties, the muscle-like and variable-stiffness behavior of DEAs without bulkiness and noise makes it favorable for wearable rehabilitation devices. Examples include active hand splints for hand/finger rehabilitation (Figure 13a) [102], ankle-foot orthosis (AFO) remedying foot drop (ankle dorsiflexion inability) (Figure 13b) [103] and compression bandages targeting the disorder of venous systems (Figure 13c) [104]. Compared to conventional passive ones with elastic bands, dynamic hand splints with folded contractile silicone DEAs enable flexible modulation of mechanical compliance and finger exercise by varying the driving voltage [102]. AFO designed with DEAs allows for lighter weight and less energy consumption with a charge recovery power system, and at the same time does not hinder plantarflexion function [104].

\subsubsection{Merits and Limitations}

As an outstanding smart material, DEAs hold promising potentials in wearable actuator technologies attributed to their intrinsic softness, light-weight and compactness, straightforward mechanism and fabrication, and high electromechanical performances. Compared to other existing actuator technologies such as shape memory alloys and electromagnetic and piezoelectric polymers, the distinctive actuation mechanism of DEAs has been reported to be capable of producing prominent resulting strain $(>100 \%)$ and stress $(\sim 7 \mathrm{MPa})$, fast response speed $(\mu \mathrm{s})$, high energy density $\left(\sim 3.4 \mathrm{MJ} / \mathrm{m}^{3}\right)$ and high efficiency $[75,78]$. In addition, the self-sensing characteristic of DEAs, i.e., the phenomenon that electrical properties such as capacitance alter under deformation, makes it possible to monitor the actuation response and develop closed-loop systems for smart human assist. Meanwhile, various challenges to some extent prevent their widespread applications in real-life scenarios. First and foremost, high driving voltage often requires an external power supply, constraining the integration of DEAs into electronic textile systems and bringing about safety concerns. Furthermore, biocompatibility, the need for additional rigid frames supporting pre-stretched films, and unstable electrical and mechanical properties are also 
crucial obstacles to overcome towards improving wearability, efficiency and sustainability of DEAs.

(a)

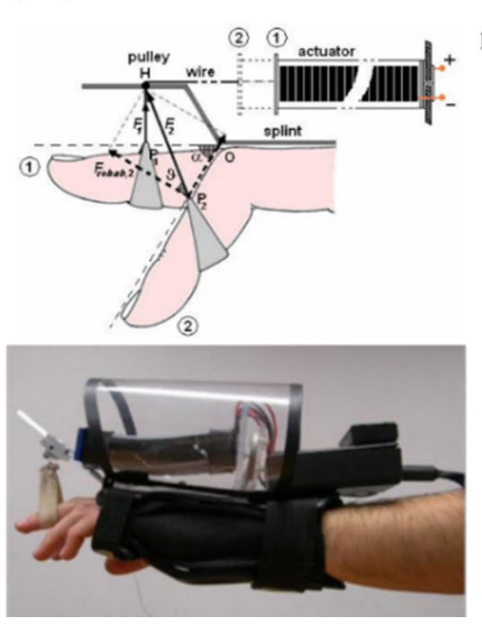

(b)

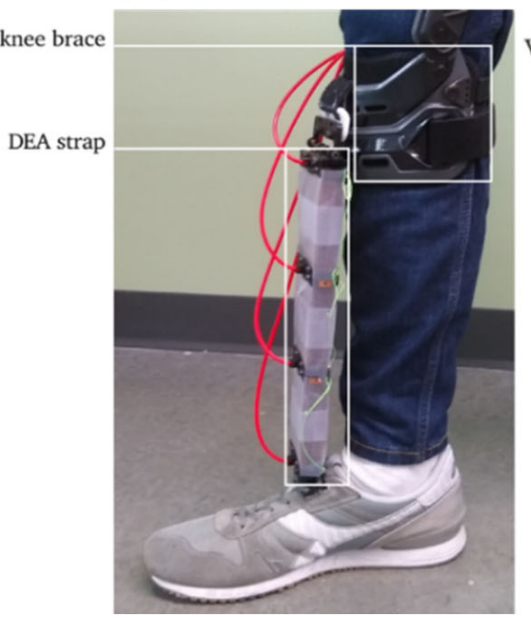

(c)

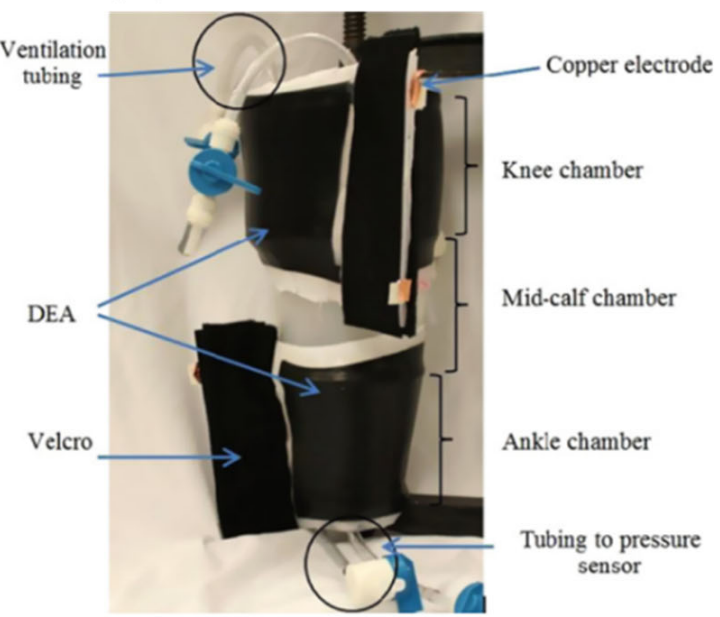

Figure 13. Schematics and prototypes of wearable DEAs for rehabilitation. (a) A schematic diagram and prototype of a DEA-based hand splint protected by a plastic guard [102]. Copyright 2008, SPIE. (b) A DEA AFO prototype consisting of a DEA strap and a knee brace [103]. Copyright 2014, IOP Publishing. (c) An active compression bandage prototype for the ankle, mid-calf and knee region [104]. Copyright 2021, Elsevier.

\subsection{Ionic-Polymer/Metal Composites and Conducing Polymers}

Ionic-Polymer/Metal Composites (IPMCs), as a category of Electroactive polymers (EAPs), have been proposed as the active material in a wide-range of applications, including biomimetic sensors and mechanical actuators [105]. Kuhn [106] and Katchalsky [107] are generally considered to be the first reporters of deformable polyelectrolytes ion solution such as polyacrylic acid (PAA) and polyvinyl chloride (PVA) systems. After that, numerous researchers have demonstrated that IPMCs can show a large deformation when placed in a time-varying electric field due to their inherent properties [108]. IPMCs can be seen as an electrolyte sandwiched by two layers of ionically conducting membranes with two electrodes. Typically, the ionically conducting membranes are made of Nafion and Flemion due to their fast response time and good durability [92]. Gold and platinum were generally used as electrodes for IPMCs. Recently, CNTs appeared as an attractive alternative material for metal electrodes due to their extraordinary electrical and mechanical properties (Figure 14a). However, compared to metal electrodes, CNTs have some limitations such as poor dispersibility and special requirements for electrolytes [109].

\subsubsection{Mechanism}

The mechanism for IPMCs varies slightly depending on the different electrodes, electrolyte and conductive membranes. Briefly, under the applied electric field, cations (or anions) in IPMCs electrolyte move to the cathode (anode) [8]. This transportation of ions generates the volumetric difference, which leads to a pressure gradient in the ionic polymer followed by a swelling of one side and shrinkage of another side of the membrane [110]. In traditional IPMCs, water was commonly used as solvent. However, water has several major problems: poor electrochemical stability in high-voltage and gradual leakage and a high vapor pressure inside a membrane due to evaporation [111]. Therefore, some researchers use other solvents such as organic solvents instead of water. Ionic liquids are considered to be a good alternative for water due to their negligible vapor pressure and high conductivity. In water driven IPMCs, the cations gather under the applied electric field squeezing out the water molecules, which create strain pressure on the ionic polymer (Figure 14b) [108]. In ionic liquid driven IPMCs, the deformation is caused by the different transfer rates of 
cations and anions. The anions moves slower to the anode due to electrostatic repulsion from the polymer matrix (Figure 14c) [110].

(a)

(b)
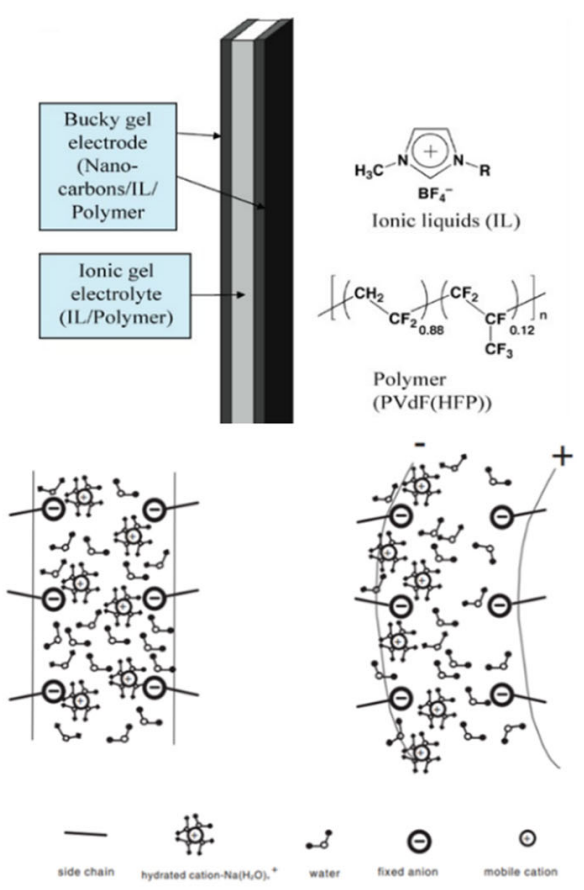

(c)
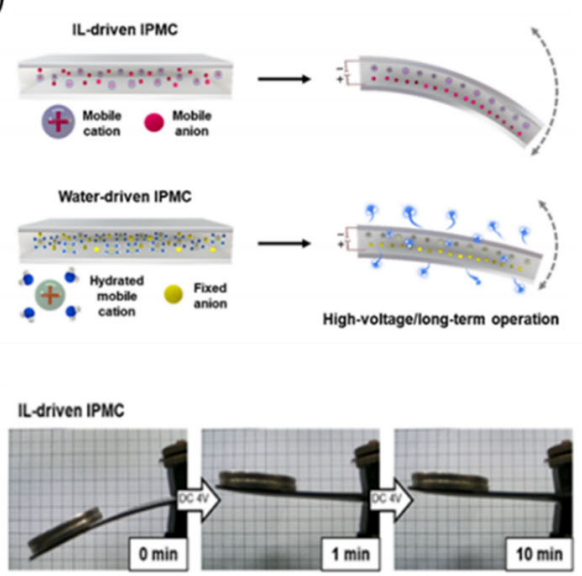

Water-driven IPMC

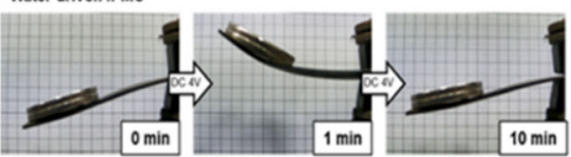

Figure 14. Schematic diagram of some IPMCs. (a) Structure of bucky-gel actuator (CNT as electrodes) [109]. Copyright 2013, Wiley-VCH. (b) A typical IPMCs and its actuation mechanism [108]. Copyright 2001, IOP Publishing. (c) Schematic illustrations of the actuation mechanism and performance differences of IPMCs driven by an IL or by water [110]. Copyright 2021, Elsevier.

Conducting polymers (CPs) are another category of EAPs which have similar mechanisms to IPMCs. CPs are typically composed of the constituent monomers of pyrrole, aniline, and thiophene and its derivatives (Figure 15) [8]. These polymers can be electrochemically oxidized and reduced repeatedly. During the redox reaction, ions can move in or out from the CPs depending on the ion (called a dopant) and the reaction [112]. Typically, there are two different reactions. When CPs contain mobile anions $\left(e^{-}\right)$, the anions will leave the polymer during reaction and the anions $\left(A^{-}\right)$in electrolyte will enter $\mathrm{CP}$ [8].

$$
(M)_{n}-m e^{-}+m A^{-} \rightarrow(M)_{n}^{m^{+}}\left(A^{-}\right)_{m}
$$

$(M)$ is the monomer, $m$ is the number of electrons transferred, and $A^{-}$is the anion responsible for maintaining the electroneutrality.

On the contrary, if CPs contain immobile anions $\left(A^{-}\right)$, they will require cations for the charge neutrality inside the polymer matrix. The cations $M^{+}$will move in and out of the $\mathrm{CP}$ during redox reaction [8].

$$
(M)_{n}+m e^{-}+m A^{-} \rightarrow(M)_{n}^{m^{+}}\left(A^{+}\right)_{m}
$$




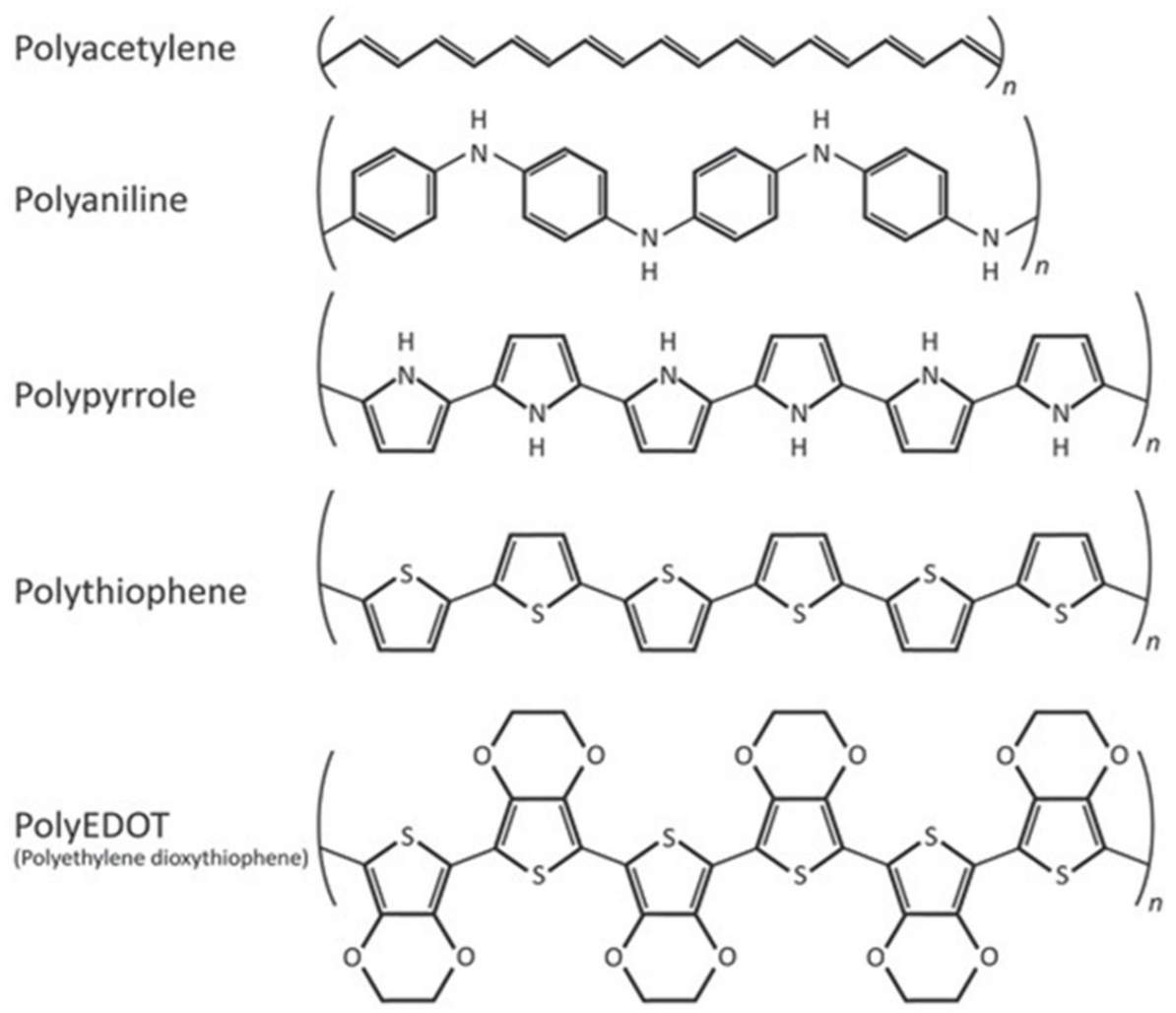

Figure 15. Chemical structure of some common CPs [8]. Copyright 2013, Wiley-VCH.

\subsubsection{Applications}

IPMCs and CPs, have been widely applied in textiles, sensors, and soft exoskeletons (Figure 16a). The electrochemical conductive polymer is combined with textile weaving technology to provide an electrochemical artificial muscle. Jager et al. reported a wearable, soft, and strain adjustable rayon fabric, which was achieved by continuously coating cellulose fibers with a PEDOT layer as a conductive electrode and a PPY layer for actuation [11]. By weaving and knitting, this actuator has an increasing output force with the increase of the number of actuator yarns. Similarly, a PEDOT:PSS coated SWCNT wired ZIF-8 structure has been reported (Figure 16b) [113]. Hydrophilization treatments enable the formation of electrode ink on the surface of the fabric and highly increase the ionic conductivity. The textile-structure actuator demonstrated large strain $(0.28 \%)$ and a high blocking force $(0.62 \mathrm{mN}$ at $0.1 \mathrm{~Hz})$. Li group demonstrated a plasticized polyvinyl chloride (PVC) gelbased exoskeleton for hip joint support. Electroresponsive hydrogels have demonstrated that they can be deformed under an electric field, similar to the mechanism of IPMCs [114]. This device can provide up to $94 \mathrm{~N}$ and 10\% biological torque at hip joints during walking (Figure 16c). In addition to being able to undergo shape changing under an electric field, some IPMCs can generate voltage under deformation, which makes them a potential sensor (Figure 16d). An IPMCs based heart rate monitoring sensor was first explored by Chattaraj et al. [115]. The mechanical impact induced by pulsating blood flow generates a potential difference on the metal plate electrode. Data retrieved from this device exhibited error percentages of $4-15 \%$ when evaluated against standard plethysmographic measures. 
(a)
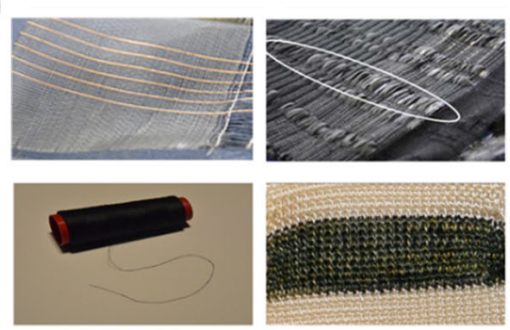

(c)

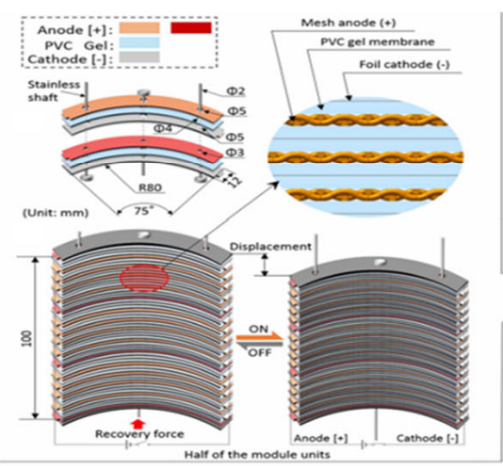

(b)
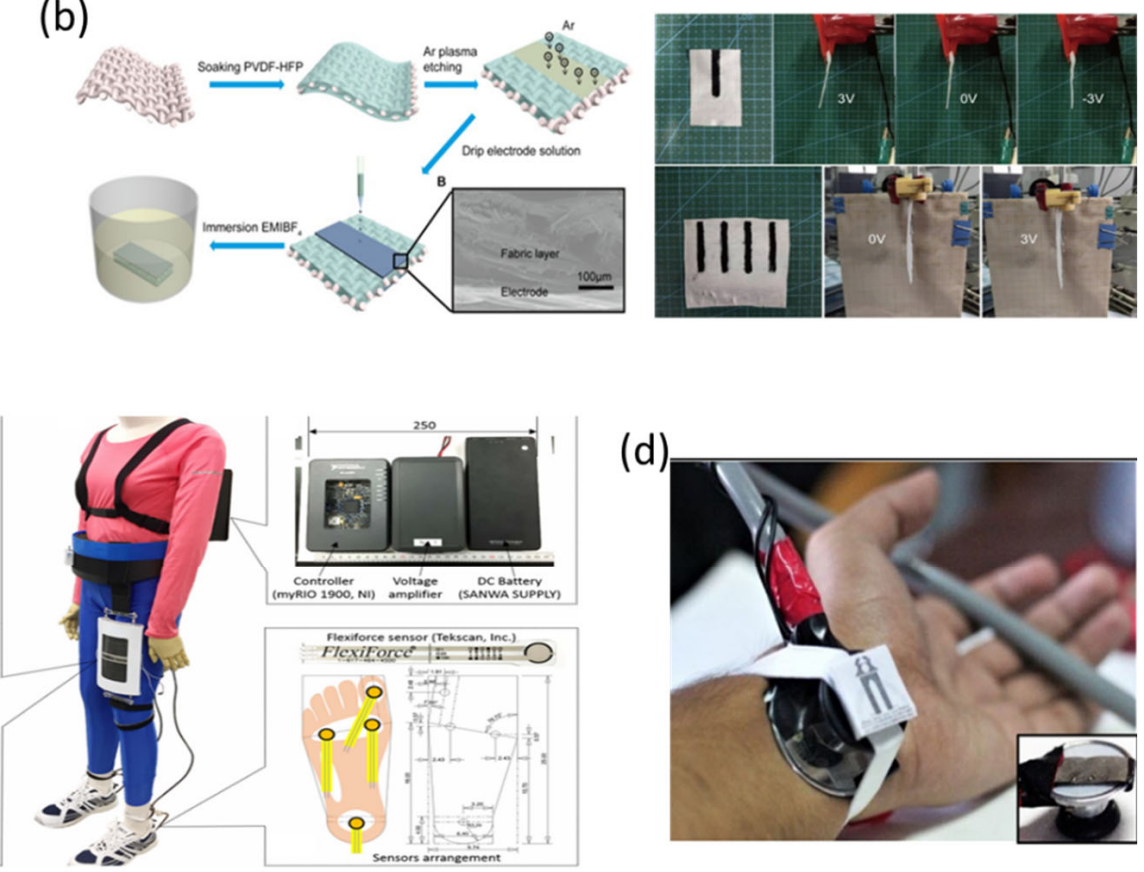

Figure 16. (a) Processing and integration of electroactive textiles [11]. Copyright 2017, the authors, published by AAAS, (b) textile actuator based on PEDOT:PSS/MOF-derivative electrode ink [113]. Copyright 2020, Wu, Yang, Li, Li and Chen. (c) PVC gel soft actuator-based assist wear [114]. Copyright 2017, IOP Publishing. (d) IPMCs based heart rate monitoring sensor [115]. Copyright 2018, Elsevier.

\subsubsection{Merits and Limitations}

IPMCs are considered to be promising actuators for practical application and have been investigated since 1965 [116]. They can deform by themselves through charge transfer. IPMCs based actuators have fast response times and good repeatability. At the same time, this type of material can be designed at a millimeter-sized scale and can work in synergy with other structures such as textile structures. Large deformation under low voltage, extremely short reaction time and high stability allow them to have unique advantages. However, the main problem of IPMCs is the poor durability due to the loss of traditional electrodes in air or liquid. There are many methods for preparing IPMCs using non-metal electrodes. The effect of these new type of electrodes needs further research. In addition, when water is used as the electrolyte solvent, problems such as ionization and leakage may occur. Although IPMCs with ionic liquid as electrolyte have good stability, their response time and actuation force are decreased. As the research progresses, the performance of IPMCS is still improving. Complicated preparation processes and expensive costs are the main limitations of IPMCs. The electrolyte and polymer matrix may have certain limitations as well.

In wearable applications, CPs are more advantageous than traditional IPMCs because they eliminate the limitations of electrodes. CPs can be considered a storage element of a capacitor that can change shape during charging and discharging [8]. Therefore, reducing their thickness can improve the response time, but it will reduce the driving force [117]. Due to the existence of the degradation potential, the ion concentration of CPs is limited [118]. The single actuation mode and low accuracy are also limiting factors in the application of such materials in wearable drives. 


\subsection{Piezoelectric Actuators}

\subsubsection{Mechanism}

Piezoelectric effect is a phenomenon in which mechanical energy and electric energy are exchanged in dielectric materials. There are two kinds of piezoelectric effect, namely positive piezoelectric effect and inverse piezoelectric effect. Positive piezoelectricity is the electric charge that accumulates in certain solid materials in response to applied mechanical stress (Figure 17a). Inverse piezoelectric effect refers to when an electric field is applied in the polarization direction of piezoelectric sensing elements; this will produce mechanical deformation or mechanical stress in a certain direction. When the applied electric field is removed, this deformation or stress will disappear (Figure 17b). The stress deformation can be divided into five basic forms: thickness deformation, length deformation, volume deformation, thickness shear deformation, and plane shear deformation.

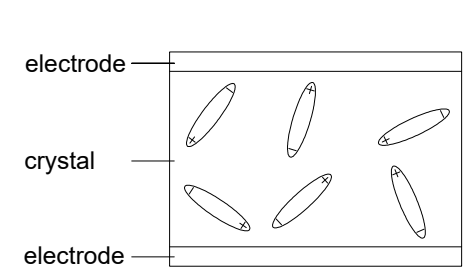

No external force

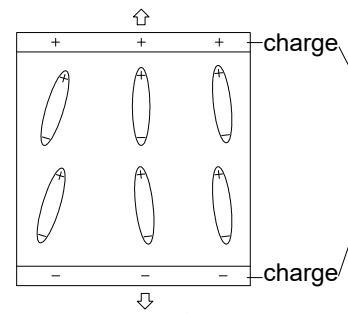

The tensile force

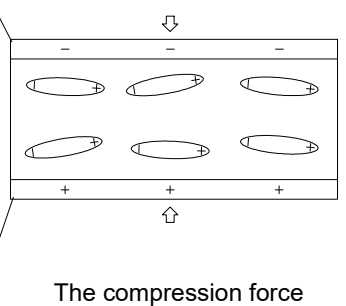

The compression force

(a) Direct piezoelectric effect__an external force causes the crystal to produce an electric charge

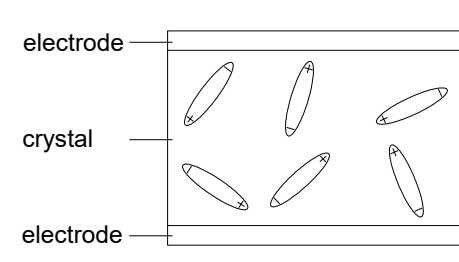

No electric field

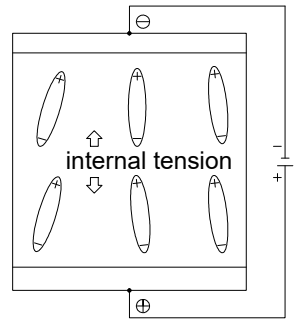

applied electric field

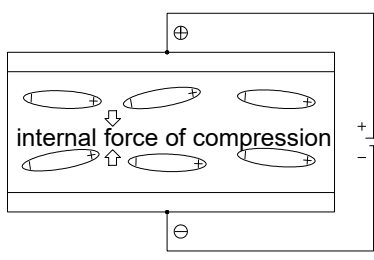

Applied reverse electric field

(b) Inverse piezoelectric_— the applied electric field causes the crystal to deform

Figure 17. Schematic diagram of piezoelectric effect. (a) Direct piezoelectric effect. (b) Inverse piezoelectric.

For piezoelectric actuators, the inverse piezoelectric effect is the basic working principle, and the governing equation can be expressed as follows:

$$
S_{j}=d_{i j} E_{i}
$$

where $S$ is the strain, $E$ is the electric field intensity, $i$ and $j$ are the electric field and strain direction respectively, $d_{i j}$ is its piezoelectric strain constant. The basic deformation mode and its main parameters are shown in Table 5 [119].

Table 5. The basic deformation mode and its main parameters.

\begin{tabular}{|c|c|c|c|}
\hline \multicolumn{2}{|c|}{ Strain Mode of Actuators } & \multirow{2}{*}{$\frac{\text { Piezoelectric Constant }}{d_{33}}$} & \multirow{2}{*}{$\begin{array}{c}\text { Strain or Displacement * } \\
S_{3}=d_{33} E_{3} \\
\triangle L_{3}=d_{33} V_{3} \\
S_{1}=d_{i 31} E_{3} \\
\triangle L_{1}=d_{31} V_{3} L_{1} / L_{3}\end{array}$} \\
\hline Stretch-extending & $\begin{array}{l}\text { Longitudinal } \\
\text { Transverse }\end{array}$ & & \\
\hline \multicolumn{2}{|c|}{ Bending } & $d_{31}$ & $Y=3\left(\frac{L}{T}\right)^{2} d_{31} V_{3}$ \\
\hline
\end{tabular}

${ }^{*}$ L: Length of piezo-wafer, T: Width of piezo-wafer. 
Piezoelectric materials include inorganic piezoelectric materials and organic piezoelectric materials [120]. Inorganic piezoelectric materials are divided into piezoelectric crystals and piezoelectric ceramics. Organic piezoelectric materials, also known as piezoelectric polymers, are being increasingly pursued for wearable applications because of their soft nature. Current piezoelectric actuators are based on organic piezoelectric materials, such as polyvinylidene fluoride (PVDF); it is necessary to mention that the PVDF piezoelectric film is softer compared to piezoelectric ceramics, light weight, has a large piezoelectric constant, high application sensitivity, good matching state, a compliance coefficient that is 30 times of PZT, and can be used in tactile measurement, mechanical measurement, energy collection, medical monitoring and so on. It is worth noting that the PVDF piezoelectric film requires polarization and stretching to improve the piezoelectric properties. Different tensile rate and other factors will affect its piezoelectric properties, but change in the preparation process can improve piezoelectric properties without additional polarization, such as electrostatic electricity. In the electrospinning process, the viscous solution is stretched and solidified into nanofibers in a strong electric field so that the molecular dipole of the polymer is oriented in the nanofiber length direction, and the transformation of $\alpha$ is converted into $\beta$ phase completion. However, PVDF-TRFE does not require additional polarization and stretching. The parameters of some piezoelectric materials are shown in Table 6.

Table 6. Piezoelectric properties of some piezoelectric materials at room temperature.

\begin{tabular}{cccc}
\hline Property & PVDF & PVDF-TRFE & PZT [8] \\
\hline Piezoelectric coefficient $\left(\mathrm{d}_{31}\right)\left(\mathrm{Pc} \mathrm{N}^{-1}\right)$ & 30 & 25 & 350 \\
Piezoelectric coefficient $\left(\mathrm{d}_{33}\right)\left(\mathrm{Pc} \mathrm{N}^{-1}\right)$ & 20 & -25 & 750 \\
Modulus (Mpa) & 2500 & 2300 & 76,500 \\
Efficiency (\%) & $75[121]$ & - & 90 \\
Stress (Mpa) & $30-50$ & - & 110 \\
Strain (\%) & $30-400$ & 0.2 & \\
\hline
\end{tabular}

\subsubsection{Structure}

The unimorph, single crystal structure is the basic structure for piezoelectric actuators. The deformation of the piezoelectric actuator depends on the basic principle of the piezoelectric inverse effect. The piezoelectric film layer is bent or elongated in alternating current; meanwhile, the passive layer is not shortened, and the stress between the two layers causes bending deformation of the piezoelectric actuator due to subsequent bending or volume mismatch. For example, Akther et al. [122] used piezoelectric single crystal actuators to amplify the haptic feedback of the vibration signal, so that humans can clearly perceive the vibration (Figure 18a,b). Wu et al. [123] combined PVDF with PET and adopted a piezoelectric single crystal structure to create a soft robot. The soft robot was bent and a leg structure was added to increase the walking speed. The soft robot has reached the rapid movement of 20 body length/s at the resonant frequency, and it can still move even if crushed one million times, demonstrating strong robustness. Maccabi et al. [124] designed three piezoelectric spiral arms using a curved piezoelectric single crystal structure which generated torsional deformation through alternating current to achieve parallel plane piston movement (Figure 18c). 
(a)

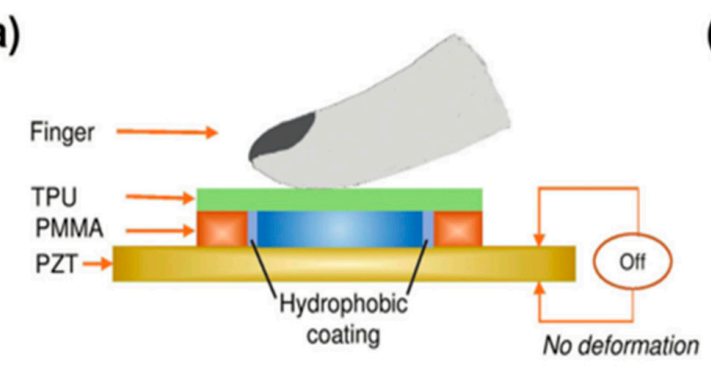

(b)

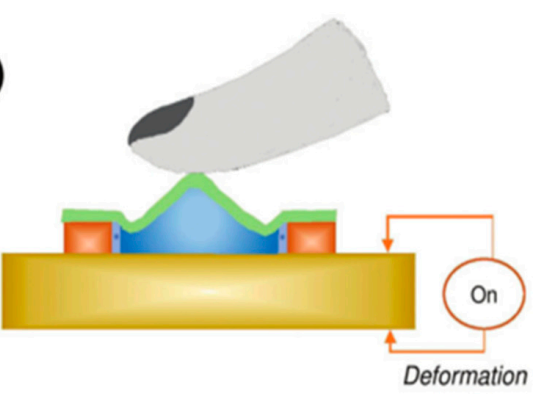

(c)

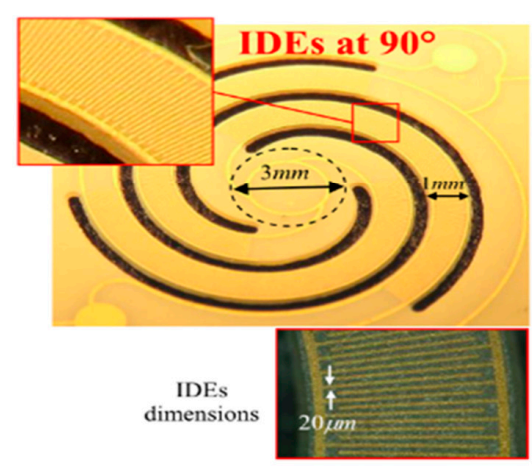

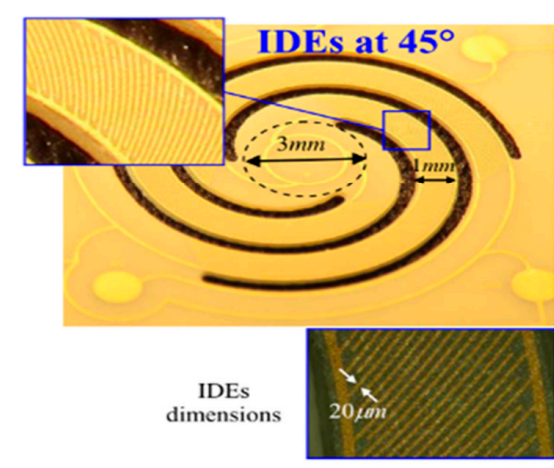

Figure 18. (a) Schematic side view of a piezoelectric actuator, which includes PZT at the bottom, glycerin/water solution in the middle, thermoplastic polyurethane (TPU) at the top and polymethyl methacrylate (PMMA) at both sides [122]. (b) Power on [122]. Copyright 2019, The Royal Society of Chemistry. (c) In the picture of the actuator, the angles between the interdigitated electrodes (IDEs) and the spiral arm are $90^{\circ}$ and $45^{\circ}$ respectively, and the spiral arm is made of PZT [124]. Copyright 2016, Elsevier.

The piezoelectric bimorph three-layer structure, has piezoelectric materials on the top and bottom layers. This structure has different mechanisms compared to the unimorph structure. The two piezoelectric film layers are bent in alternating current. One of the piezoelectric sheets is elongated, and the other is shortened, and their bending strain is enlarged. The advantage of this structure is that it doubles the displacement of the soft robot and achieves more excellent moving characteristics. Piezoelectric ceramics are widely used in this structure. For example, $\mathrm{Xu}$ et al. [125] developed a piezoelectric actuator that can rotate rapidly. When using a piezoelectric bimorph structure, driven by piezoelectric vibration, the maximum rotation speed is as high as $118.3 \mathrm{r} / \mathrm{min}$. Kwon et al. [126] developed a mobile phone vibration driver by using bimorph piezoelectric ceramics. This structure can also be applied in other materials; for example, Park et al. [127] used the upper and lower layers of PVDF piezoelectric film and magnetic tape as the main body and the PVDF piezoelectric film and magnetic tape as the legs to make the soft robot. Under the $160 \mathrm{~Hz}$ resonance frequency, the robot applied $\pm 65 \mathrm{~V} \mathrm{AC}$ voltage and achieved a good mobility performance of $35.3 \mathrm{~mm} / \mathrm{s}$.

In addition, according to the direction of vibration, the piezoelectric actuator can be divided into a longitudinal structure [128], a longitudinal bending structure [129], a longitudinal torsion [130], and a curved bending structure [128]. The length affects the modal frequency of the longitudinal structure, and length and cross-sectional dimensions structure affect the modal frequency of the bending and torsional structure [131].

\subsubsection{Applications}

Piezoelectric sensors have many applications in the medical field to detect human health, and much wearable research has also demonstrated great potential for them in biomechanical energy collection. Moreover, piezoelectric actuators can be applied in various fields, such as miniature pumps and piezoelectric motors, etc. This section mainly introduces the application of piezoelectric drivers in wearable applications. Wearable 
devices based on piezoelectric actuators are light in weight, especially organic piezoelectric materials, which can be made very thin and move unconstrained. Theoretically, there are many applications for piezoelectric actuators in wearable applications. First, piezoelectric actuators can be directly applied to the skin to recognize fonts or objects and their colors through vibrational tactile feedback. For example, Sauvet et al. [132] study a wearable actuator that can make the skin feel. Through experiments they verified that people can correctly perceive the location and strong level of vibration when piezoelectric actuators achieve vibration response with the index finger and palm soft contact. This further improves the user interaction with the product, while providing inspiration for identifying fonts, color and so on (Figure 19a). Additionally, Zhu et al. [133] developed a tactile feedback smart glove. Its accuracy of the target recognition can reach $96 \%$, in which the piezoelectric unit is applied to PZT, the main function is to use the reverse piezoelectric effect to vibrate and stimulate the touch. They can achieve a different interaction result by adjusting power at a resonant frequency (Figure 19b). Piezoelectric actuators also have applications in medicine. For example, in the study of Dagdeviren et al. [134], PZT piezoelectric plates, where the actuator is the larger part and the sensor is the smaller part, were installed on the human skin surface. The combination of the driver and the sensor was used to accurately measure the elastic modulus of the skin and predict the pathophysiological conditions.
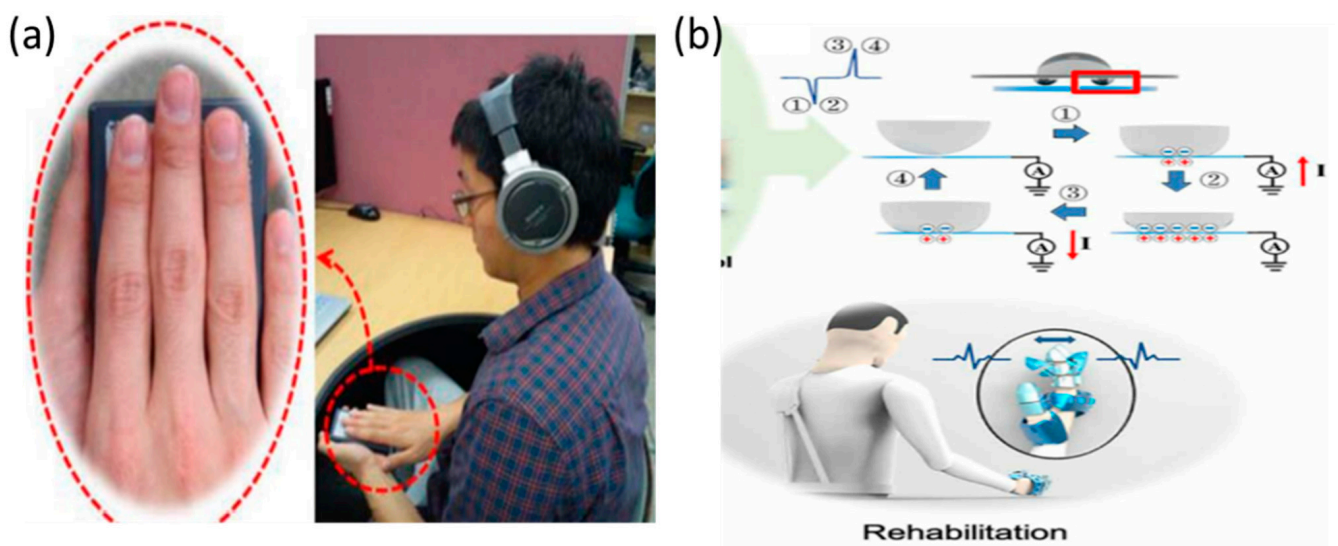

Figure 19. (a) The experimenter touched the piezoelectric actuator and felt the vibration [132]. Copyright 2017, Elsevier. (b) Wearable gloves vibrate to irritate finger skin [133]. Copyright 2020, the authors, published by AAAS.

\subsubsection{Merits and Limitations}

Advantages of the piezoelectric actuator include a simple manufacturing method, and for organic piezoelectric polymer with the flexible combination of organic ground substance, advantages include good flexibility, light quality, good sensitivity, small size, and low power consumption. Additionally, compared with the traditional rigid or general shape memory alloy's heat, humidity, $\mathrm{pH}$ value, and chemical stimulation, the piezoelectric actuator has the advantage for quick response. Theoretically, this kind of soft robot has infinite degrees of freedom. It can be in smooth contact with the skin, integrate sensors and actuators, and can make small self-driven devices by using piezoelectric power generation. Its limitations are mainly manifested in the small amplitude of motion in the wearable, the required voltage is large, and the combination of textile problems.

\subsection{Electromagnetic Actuators}

\subsubsection{Mechanism}

Recently, electromagnetic actuators have been widely used in robots and wearable tactile feedback devices. Electromagnetic actuators are mainly composed of energized coils and magnetic materials, and the interaction force generated between them is used as the power source. The basic mechanism of action is mainly divided into two situations. 
The first situation is that it is affected by magnetic force or magnetic moment, causing deformation/displacement of the magnetic object, which is expressed as follows [135]:

$$
\begin{gathered}
f_{m}=\int_{V m}(M \cdot \Delta) d V_{m} \\
\tau_{m}=\int_{V m}(M \times B) d V_{m}
\end{gathered}
$$

where $f_{m}$ is the magnetic force experienced by a magnetic field, $\tau_{m}$ is the magnetic moment experienced by an external magnetic field, $M$ is the magnetization of the external magnetic field, $\Delta$ is the gradient of the gradient magnetic field, $V$ is the volume of the magnetic shield, and B is the magnetic flux density of the external magnetic field.

The second is that the electrified conductor is deformed by Lorentz force in the external magnetic field, which is expressed as follows [136]:

$$
F=I \int d l \times B
$$

where $F$ is the Lorentz force, $I$ is the current through the wire, $l$ is the length of wire, and $B$ is the magnetic flux density of the external magnetic field.

At present, the driving magnetic field of many electromagnetic actuators is generated by the energized coil, and the magnetic flux density generated by them conforms to the Biot-Saffar law, which is expressed as follows [137]:

$$
\vec{B}=\int_{L} \frac{\mu_{0} I}{4 \pi} \frac{d l \times \overrightarrow{e_{r}}}{r^{2}}
$$

where $I$ is the current through the wire and does not change with time, $d l$ is an infinitesimal segment of the wire, $e_{r}$ is the unit vector of the current element pointing to the field point to be solved, $\mu_{0}$ is the permeability of vacuum.

\subsubsection{Structure}

Electromagnetic actuators used in wearable tactile devices are usually composed of coils, magnets, vibration generating parts, and flexible materials. The changing magnetic field generated by the coils drives the magnets to move. The movement of the magnets and the vibration generating parts will cause the surface of the human skin to be generated. The tactile and vibration generating part is usually a rigid shell, and the flexible material is usually wrapped around the outside of the device to fit the skin. For instance, the wearable electromagnetic actuator researched by Pece et al. uses [138] this type of structure. The common magnetic materials that have been reported in the literatures and include nickel-plated neodymium and NdFeB magnet and the Flexible materials include PMMA, parylene, polyimide and PDMS elastomer [139].

The electromagnetic actuator can not only move in a straight line, but also complete the bending effect. It can be used as a soft gripper. For instance, Do et al. [140] demonstrated a flexible electromagnetic actuator. The magnet is mounted on the flexible beam and driven by the magnetic field generated by soft $3 \mathrm{D}$ coil to achieve bending deformation (Figure 20a). 
(a)

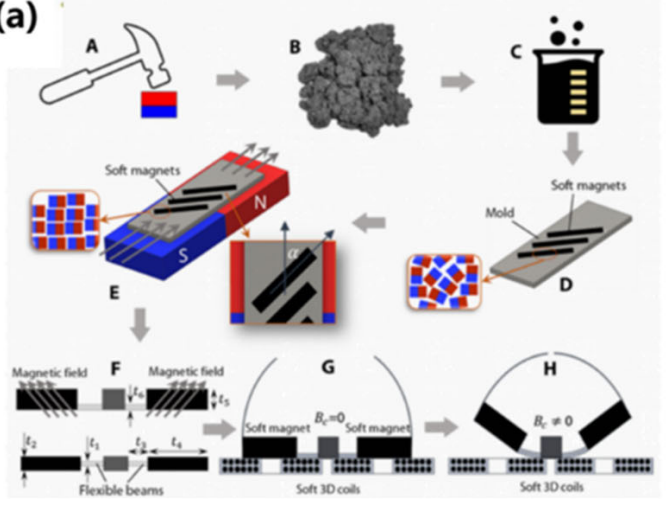

(b)
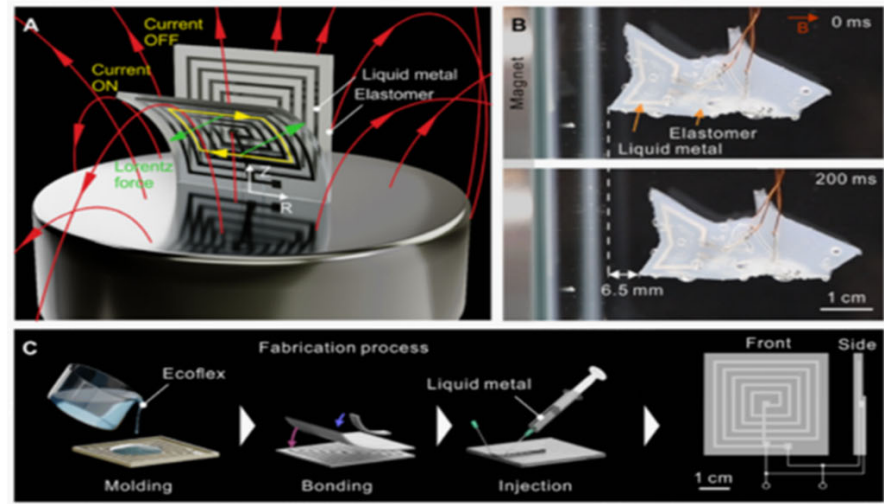

Figure 20. Structure of electromagnetic actuators. (a) Electromagnetic actuator with bending motion [140]. Copyright 2018, Wiley-VCH. (b) Electromagnetic actuator composed of liquid metal coil (69\%gallium, 22\%Indium, 9\%tin) and silicon elastomer [136]. Copyright 2020, the authors, published by AAAS.

Recently, many scholars have studied a new structure of electromagnetic actuator that uses liquid metal instead of traditional copper as the coil for the electromagnetic actuator and is integrated into flexible materials. When the flexible coil is energized, it is driven by Lorentz force. This kind of structure has more degrees of freedom than traditional structures. For instance, Mao et al. [136] embedded liquid metals (69\% gallium, $22 \%$ indium, $9 \%$ tin) into silicon elastomers to replace traditional metal coils as an actuator. The soft actuator is placed on the flat magnet, and the Lorentz force generated by different types of voltage signals makes the actuator move in different ways. They use actuators as fins, agitators, etc. to demonstrate their greater deformability (Figure 20b). Likewise, liquid metal coils made of Ga-In alloys are also used in soft electromagnetic actuators. The actuator that was composed of a liquid metal coil, and PDMS could reach a maximum displacement amplitude of $21.5 \mathrm{~mm}$ [141].

\subsubsection{Applications}

Among wearable devices, electromagnetic actuators are an area that has not yet been completely developed. Due to their advantages of low driving voltage and large deformation, it is one of the important directions for the future development of wearable tactile devices. Ozioko et al. demonstrated [142] a dual-function wearable tactile device that can collect tactile information and provide tactile vibration feedback. The tactile feedback component was realized by an electromagnetic actuator composed of flexible coils and permanent magnets assembled in PDMS. The tactile collection component was realized by the tablet capacitor; these components were integrated. The information was transmitted between deaf-blind and sighted and hearing individuals via a mobile app through different touch and vibration modes, similar to Morse code (Figure 21a). In their later work, they made gloves for communication between the blind [143]. In each pair of gloves, six tactile devices were placed on the index finger, middle finger and ring finger of each glove, representing six points in Braille. The tactile feedback information generated by tactile device and the collected touch information were processed by the microcontroller integrated on the glove and transmitted wirelessly through the Bluetooth module (Figure 21b). 
(a)
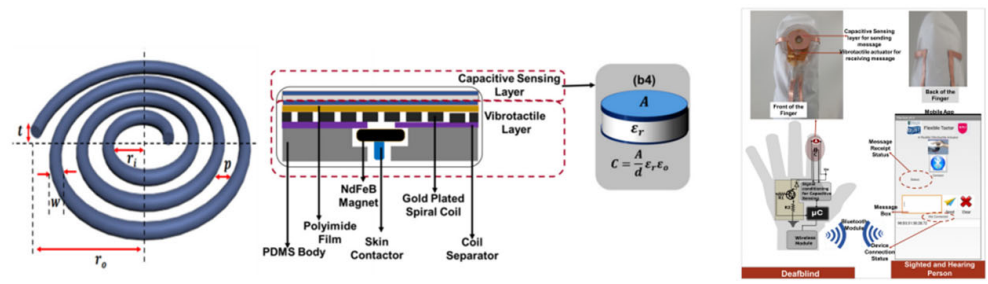

(b)
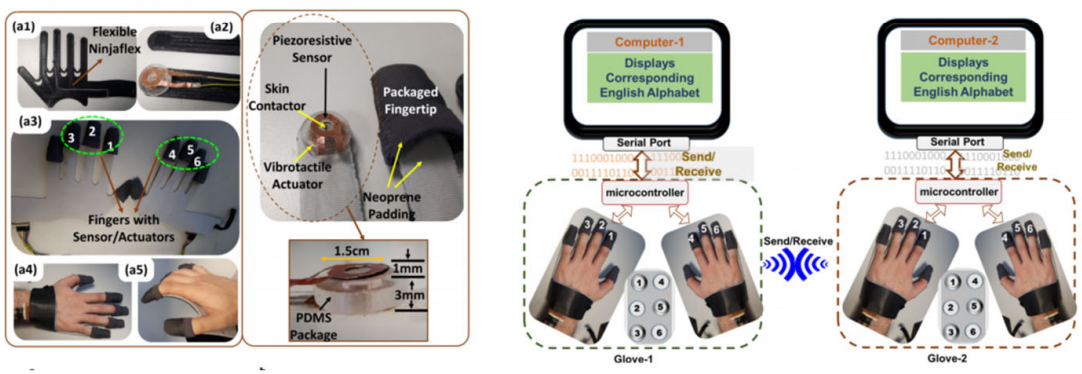

Figure 21. Application of electromagnetic actuators in wearable devices. (a) Working principle of dual-function wearable tactile device [142] copyright 2020 by the authors. Licensee MDPI, Basel, Switzerland. (b) Structure and application of tactile feedback glove [143]. Reproduced under the terms of the CC-BY Creative Commons Attribution 4.0 International License (https: / / creativecommons. org/licenses/by/4.0/), Copyright 2020, published by IEEE.

Likewise, Rogers et al. integrated 32 electromagnetic actuators with a wireless power supply as wearable devices for tactile feedback. The primary coil obtained power from the outside to supply power to the coil, so as to drive the magnet to vibrate. The force acting on the skin of the actuator with the input power of $1.75 \mathrm{~mW}$ was $135 \mathrm{mN}$, and the NFC antenna received control information from the outside. Each actuator can be controlled individually. This device can be applied in games, helping the disabled, and in other fields $[133,144]$.

\subsubsection{Merits and Limitations}

Generally speaking, the electromagnetic actuator has the advantages of low driving voltage (typically from 0 to $30 \mathrm{~V}$ ) [140], fast response speed (millisecond) [144] and large displacement, but it is difficult to be completely flexible. Furthermore, most electromagnetic actuators must be driven by wires or in an external driving magnetic field, which cannot achieve remote wireless control.

\subsection{Liquid Crystal Elastomer}

\subsubsection{Mechanism}

Liquid crystal polymers are materials that exhibit liquid crystallinity and can be divided into liquid crystal elastomers (LCEs) and liquid crystal polymer networks (LCNs) [145]. Compared to LCNs, LCEs consist of loosely crosslinked liquid-crystal sidechain and/or main-chain mesogenic units with a low crosslink density, which cause greater deformability and flexibility [146]. LCEs can undergo reversible transitions between polydomain, monodomain, and isotropic phases (Figure 22). These different phases depend on the orientation of mesogens, which normally refers to the aromatic groups [147]. Phase transition from polydomain to monodomain can be achieved through mechanical deformation while the phase transition from monodomain or polydomain to isotropic can be achieved through heating up the temperature above isotropic clearing temperature $\left(T_{i}\right)$ [148]. They have large $(\sim 40 \%)$ and reversible actuation, high processability, and programmability, making LCEs a desired material for soft actuators. 


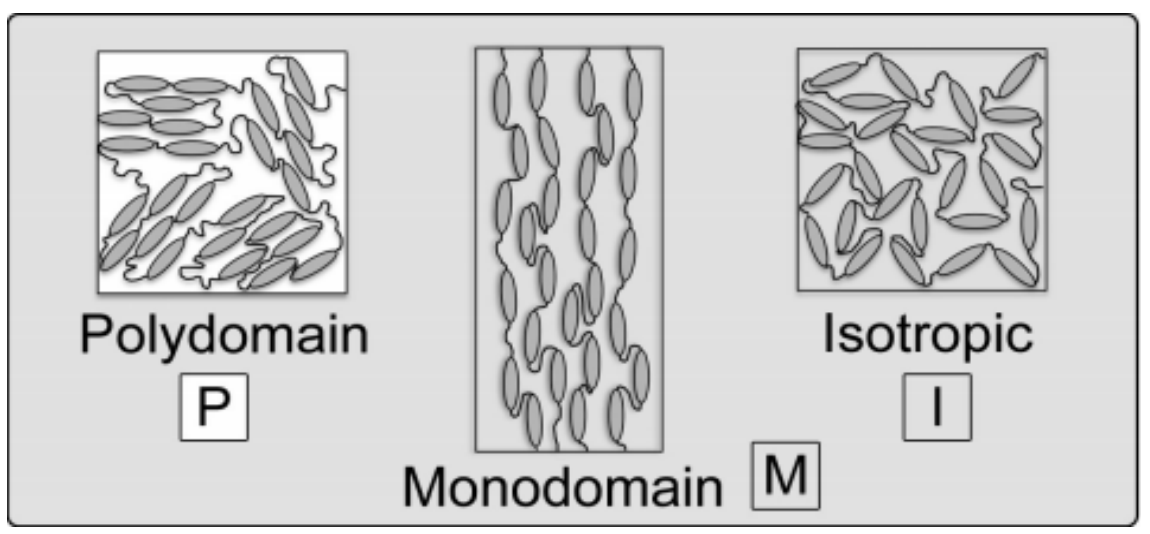

Figure 22. Schematic of different phases of LCE.

\subsubsection{Structure}

LCEs based on a two-stage thiol-acrylate Michael addition and photopolymerization (TAMAP) reaction were reported by Yakacki et al. [149]. Two step reactions allow for pre-stretch before full crosslinking of polymer networks, which enable up to $100 \%$ strain for actuation. Cai et al. reported an LCE artificial muscle film using the two step reaction. By embedding heating wires, this artificial film can lift a load of $3.92 \mathrm{~N}$ (the stress was $0.312 \mathrm{MPa}$ ) by $38 \%$ of its initial length under electrical control [148]. An electrically actuated soft artificial muscle made by flexible electrothermal film and liquid crystal elastomer was reported by Liu et al. [150]. The LCE was assembled with MWCNT/AgNW composite to achieve fast responsive uniform temperature deformation and constant resistance. At $6.5 \mathrm{~V}$, a saturation temperature of $189^{\circ} \mathrm{C}$ can be reached with a heating rate of $21^{\circ} \mathrm{C} / \mathrm{s}$, leading to a work density of $9.97 \mathrm{~kJ} / \mathrm{m} 3$ and an actuating stress of $0.46 \mathrm{MPa}$.

Beside direct heating and electrical heating, photothermal actuation is another common method to trigger the deformation of LCE. To achieve photothermal control, conventional energy converters such as gold nanoparticles, carbon nanotubes and liquid metals have been reported to apply in the LCE matrix. An AuNR/LCE film reported by Yang et al. obtained a $100^{\circ}$ bending angle under laser $\left(800 \mathrm{~nm}, \approx 1.0 \mathrm{~W} / \mathrm{cm}^{2}\right)$ (Figure 23a) [151]. Yang et al. demonstrated a heat/UV/near-infrared (NIR) triple-stimuli-responsive LCE material using a two-step cross-linking process coupled with a uniaxial stretching technique [152]. Carbon nanotubes (CNTs) enable the conversion of near-infrared light to thermal energy while the azobenzene group A44 V6 can trigger the deformation under UV light (Figure 23b). Ware et al. exhibited a 4D-printed LM-LCEs which can absorb NIR $(730 \mathrm{~nm}$ ) (Figure 23c) [153]. By the dispersion of Eutectic gallium-indium (EGaIn) in LCE, the composite is $4 \mathrm{D}$-printable to different patterns, achieving up to $150^{\circ}$ bending angle under $800 \mathrm{mw} / \mathrm{cm}^{2}$ NIR light within $40 \mathrm{~s}$.

Photoisomerization is another mechanism for photoexcited actuators. Polymers with azobenzene, diarylethene and spiropyrans functional group can undergo cis-trans photoisomerization transitions triggered by radiation with high energy photons [154]. This microscopic chemical structure change can cause macroscopic deformation to a certain extent. This method normally accompanies other polymer networks to induce photoexcited actuation and improve deformability. Priimagi et al. designed a self-regulating iris based on light-actuated liquid crystal elastomer (Figure 23d) [155]. It can automatically adjust the shape by reacting to the power density of the incident light. When the light intensity increases, the device will close, and when the minimum pupil size is reached, the light transmittance is reduced to one seventh. 
(a)

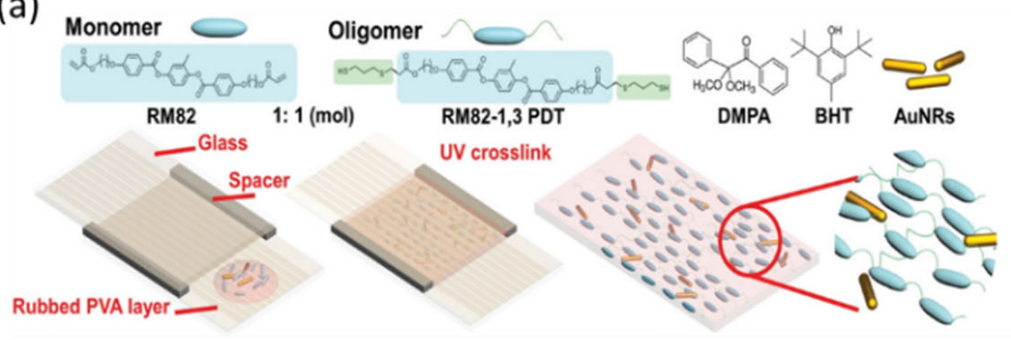

(b)

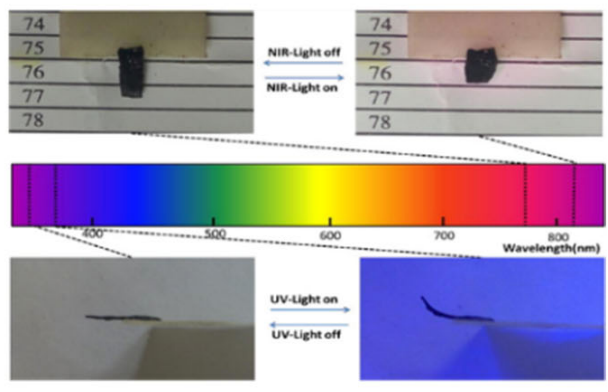

(c)

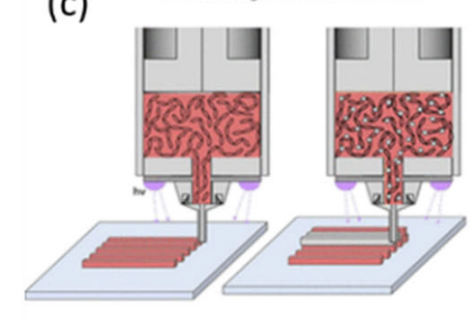

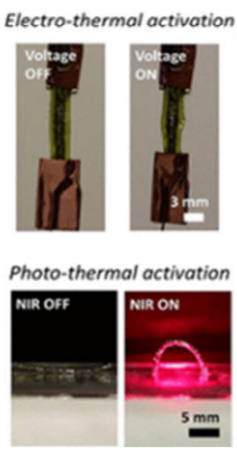

(d)

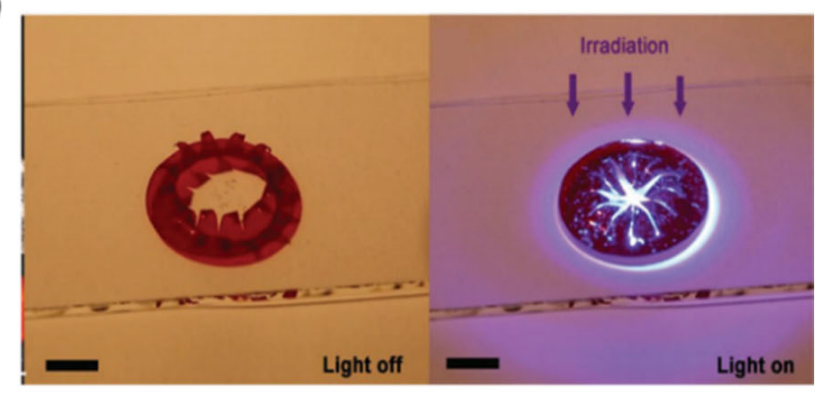

Figure 23. Modification of LCEs for multi-actuation modes. (a) Illustration of the fabrication process of AuNR/LCE films [151]. Copyright 2018, Wiley-VCH. (b) NIR/UV actuated CNT/Azobenzene/LCEs [152]. Copyright 2016, American Chemical Society. (c) 4D-Printable Liquid Metal-Liquid Crystal Elastomer Composites [153]. Copyright 2016, American Chemical Society. (d) Light-actuated LCE [155]. Copyright 2017, Wiley-VCH.

\subsubsection{Applications}

The main applications of LCE in wearable actuators are artificial muscles, smart textiles and exoskeletons. Qi et al. demonstrate a loom woven smart textile using LCE fibers [156]. LCE undergoes shrinkage during heating process, which creates pores in the textile. This shrinkage starts at $40^{\circ} \mathrm{C}$ and reaches the maximum at $80^{\circ} \mathrm{C}$. After cooling, the LCE fiber expands and the textile returns to its original shape (Figure 24a). These results indicate that LCE can use loom weaving to create a stimulus responsive, two-way shape memory textile. Inspired by vascular artificial muscle, Cai et al. designed a vascular LCE-based artificial muscle (VLAM) which showed a potential application for LCE to be used as exoskeletons (Figure 24b) [157]. With the injection of hot and cold water in its internal fluidic channel, VLAM achieved fast thermal actuation and recovery, and can be applied in a wide range of external temperatures. In Figure 24b, VLAM demonstrated different actuation modes of motion of a skeleton model.

\subsubsection{Merits and Limitations}

LCE has outstanding advantages such as large deformation, softness, multi-function, multiple response modes, durability, etc. However, the limitation of LCE as a wearable actuator material lies in its inherent properties. Phase changing from isotropic to smectic can only be induced by heating, which restricts its application. Although a variety of actuation modes have been achieved through the modification of LCE, they are realized through the form of energy conversion. In addition, the excessively high driving temperature of LCE $\left(>100^{\circ} \mathrm{C}\right)$ hinders its application on the human body. Some research has shown that the LCE molecular structure can be modified to reduce its driving temperature $[158,159]$. However, it will weaken the performance. Aside from these, slow response speed is a major problem. However, its excellent deformability, structure stability and processability endow its significant advantages as actuator. The application of LCE as a wearable actuator still needs further research. 
(a)

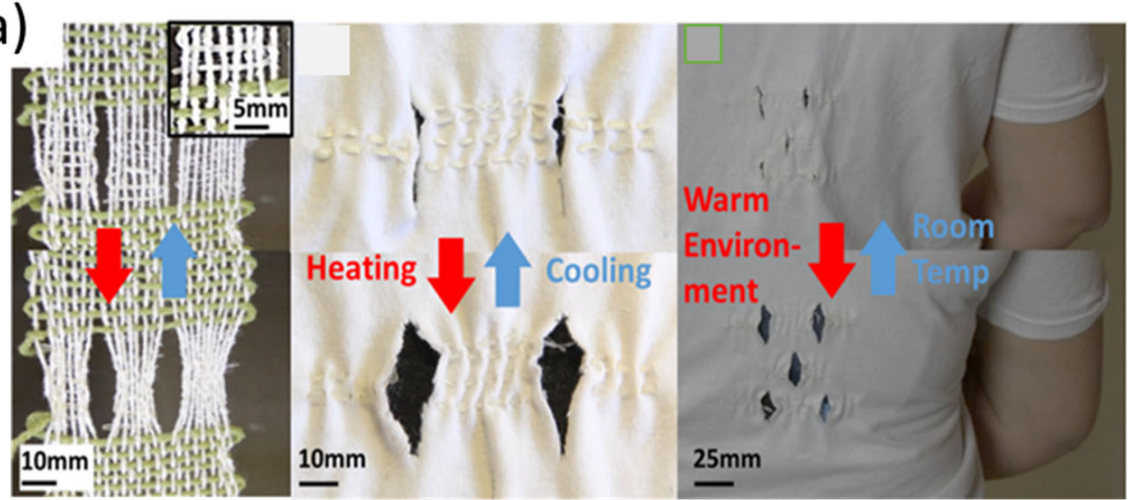

(b)
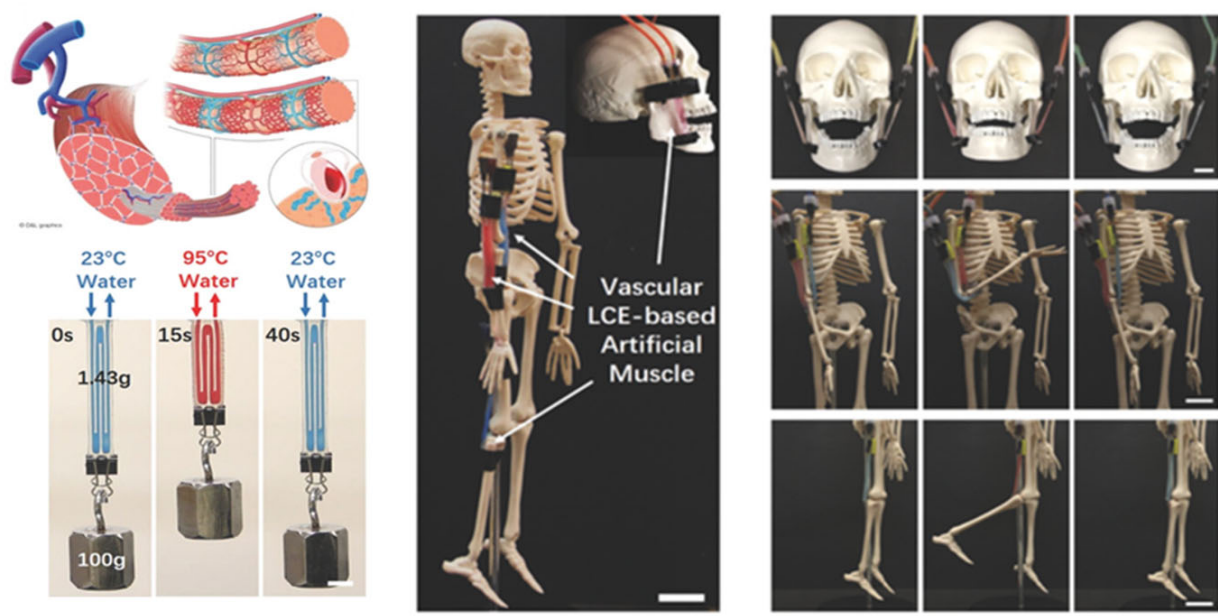

Figure 24. Wearable LCE actuators. (a) LCE based thermal management textile [156]. Copyright 2019, American Chemical Society. (b) A vascular LCE-based artificial muscle (VLAM) [157]. Copyright 2018, Wiley-VCH.

\subsection{Other Actuators}

\subsubsection{Electric Motor}

Besides pneumatic and hydraulic actuators, electric-driven actuators are also widely applied in exoskeletons. Compared to pneumatic or hydraulic actuators, electric actuator systems inevitably come with many problems, such as: friction, stiffness, electrical disturbance and complex systems [13]. Nevertheless, electric actuators are still the most common actuators in the industry due to their irreplaceable processability and designability. Gassert et al. present a wearable glove system for grasping assistance [160]. Due to a compliant finger mechanism and versatile thumb mechanism, this system can provide assistance for the most commonly used grabbing exercises. An exoskeleton that can assist walking and running separately was first reported by Kim et al. [161]. Through the electrical motors connected to the cable, this device applies tension between the waist belt and the thigh wrap, creating an external extension moment around the hip joint. Based on the estimation of potential energy fluctuation of the wearer's center of mass, this device can switch the actuation modes between running or walking.

\subsubsection{Carbon Nanotubes}

Carbon nanotubes (CNTs) have attracted great interest in recent research due to their distinguished mechanical, electrical and chemical properties [162]. With the advancement of process methods, carbon nanotube-based sensors, electrodes, actuators and energy storage materials have been widely used in smart systems. In particular, CNTs-based yarns with twist, or introducing a yarn structure in CNTs, can further enhance its flexibility, allowing it to be used in actuators such as artificial muscles [163]. By far, researchers 
find that CNTs can be actuated by electrical, chemical, thermal, or photonic power [164]. Among them, electrochemical actuation of CNTs received special attention [165]. Compared to electrothermally driven CNT yarns, electrochemical driven CNT yarns provide higher efficiencies and larger torsional or tensile actuation with lower voltage requirements [166]. Similar to CPs, the mechanism of electrochemical actuation is the strain and volume change on the graphene layers induced by electrochemical double-layer charge injection (Figure 25a) [162]. Foroughi et al. have first demonstrated a torsional and rotational CNT yarn which can provide a reversible $15,000^{\circ}$ rotation and 590 revolutions per minute. [167]. This kind of CNT yarn, which was twist-spun from forests of multiwalled carbon nanotubes (MWCNTs), can undergo partial untwisting in the electrolyte applied with an electric field to achieve actuation. Kim et al. have designed a hierarchically twisted electrochemical driven CNT yarn with a maximum tensile stroke of $15.1 \%$ and work capacity of $3.78 \mathrm{~kJ} / \mathrm{kg}$. [168]. This twisted and coil structure achieves the transformation of electrochemical driven CNT yarn from rotation actuation to stretching actuation (Figure 25b).

CNTs yarn can be considered as CPs and applied into textile structures. For example, they can be fabricated with other yarns or applied in smart textile systems. However, due to their poor stretchability, high cost and low energy conversion efficiency, CNTs based wearable actuators need further research. For more detail about CNTs actuators, we refer to a review by Jang et al. [163].

(a)

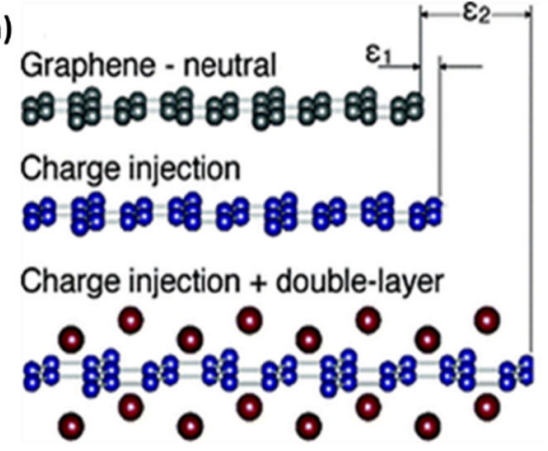

(b)

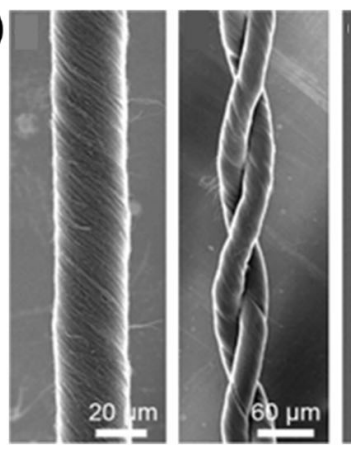

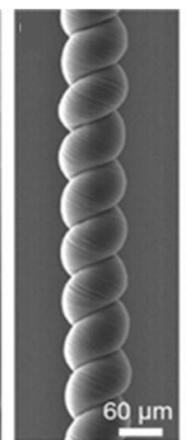

Figure 25. (a) Schematic of the mechanism for electrochemical actuation of CNT [162]. Copyright 2015, Elsevier. (b) MWNT yarn structures for torsional and tensile actuation [166]. Copyright 2014, American Chemical Society.

\subsubsection{Hydrogels}

Stimuli-responsive gels refer to a category of hydrogels that can respond to external stimuli. These stimuli include temperature, electric field, light and $\mathrm{PH}$ change. The mechanism of actuation of hydrogels is similar to the material mentioned in Section 2. These materials are widely used in biomedical applications and wearable actuators. The exoskeleton made by PVC gel in Section 2 is one example of hydrogels as wearable devices. The chemical stability and durability are the limitation for them to be applied in wearable actuators. For more information we refer to a review by Mirvakili et al. [8].

\subsubsection{Organic Molecule-Driven Polymeric Actuators}

Organic molecule-driven polymeric actuators can be defined as actuators that can have mechanical motions induced by organic solvents. This driving principle is usually the volume change or molecular structure change caused by the absorption and release of the organic solution. For example, LCEs can generate inhomogeneous swelling when absorbing polar organic solvents. Such materials can also be twisted into artificial muscles. However, the actuation mechanism and complex synthesis process are the major problems. For detailed information, we refer to a review of Lin et al. [169]. 


\section{Outlook}

Recent applications of wearable actuators are mainly concentrated in three categories: wearable robots, haptic devices, and personal thermal regulation textiles. Current orthosis robots are dominated by electric motors [18], which are high-output, stable, multifunctional, but also bulky, stiff, and inconvenient. In the future, these rigid electric motors will be gradually replaced by high-performance soft and smart materials, although they have a long way to go. For pneumatic and hydraulic actuators, research on the structure and functional design enables this type of actuator to achieve complex motions with simple strategies. Further, the efficiency of these actuators has been improved through the integration of motors, pumps and valves [170]. Recently, the combination of pneumatic and hydraulic actuators and textiles allows us to see new possibilities [22] which make the pneumatic/hydraulic wearable robots not limited to medical treatment and rehabilitation. With the emerging material science and technology, new smart materials enable the possibility of wearable robots, getting rid of bulky, rigid, and heavy equipment. Thermally driven materials such as shape memory alloys have problems such as high thermal hysteresis, high temperature, and high cost [29]. The actuation force of IPMCs, CNTs and CPs is too small, and it is difficult to make large-scale devices [18]. Among these new materials, DEAs are the most promising, due to fast response speed, high electromechanical performances, and high efficiency [18]. The research direction of reducing the operating voltage, improving the stability, and structure design of DEAs will be the mainstream. Wearable orthosis robots require high output force and precise control, especially for lower limb rehabilitation, which needs to be addressed in the future. Moreover, ideal combination of textile structure and smart materials for wearable robots is still a major challenge and we look forward to seeing more wearable assistive robots based on textile structures in the future.

Virtual and augmented reality (VR/AR) technology is a system that generates perceptual information through a computer and interacts with the real or virtual world. As the $\mathrm{VR} / \mathrm{AR}$ technology evolves, the market demands matching or even better performance equipment. Haptic technology is an indispensable part of the VR/AR system. Wearable haptic devices mainly include three different methods: skin-attachable haptic interfaces, wearable haptic interfaces, and touch-based haptic interfaces [171]. Traditional haptic feedback is usually achieved by using the vibration motor such as the eccentric rotating mass (ERM) and linear resonant actuator (LRA) [171]. These actuators have the problems of poor portability and low resolution. Fine tactile feedback can be achieved through fine texture and tiny shapes, which makes soft actuators a potential alternative [171]. Soft actuators such as dielectric, electromagnetic, and piezoelectric actuators have been widely applied in this field. Future research is likely to take the advantage of soft materials to achieve multi-point stimulations and multi-shape generation [171]. Moreover, reducing the driving voltage and increasing the reliability of materials are also main research directions. Integration of haptic actuators and textiles into smart textiles to replace traditional tactile feedback devices is another potential for breakthrough of haptic technologies.

Thermal regulation textiles, as the first generation of smart textile, have been used in commerce and the market for decades [1]. These textiles are typically made of materials (nylon, wool, silk etc.) that can undergo expansion by moisture or heat. Through structural design such as twisting or chemical modification, these materials can passively respond to environmental stimuli. Future research may lie on the improvement of material performance and the design of the active regulation system.

Due to the advantages of programmability and comfort, textiles are very likely to be the main implementation method for wearable actuators. The new soft material has good compatibility with the textile structure. CNTs, shape memory alloys, and LCEs can be directly used as yarns for textile design. As an indispensable element of human life, textiles can also serve as a carrier of actuators. How to achieve actuation without affecting the original function of the textile is a problem that needs to be overcome. 


\section{Conclusions}

In this review, we summarized the materials and structures that can be applied to wearable actuators including pneumatic and hydraulic actuators, shape memory alloys and polymers, thermal and hygroscopic materials, dielectric elastomers, ionic and conducting polymers, piezoelectric actuators, electromagnetic actuators, liquid crystal elastomers, etc. We have cited examples of wearable applications recently reported. These actuator applications are mainly concentrated in orthosis robots, haptic actuators, and smart textiles. There is no doubt that the application prospects of smart wearable actuators are wide, and the research of new soft actuator materials and structures is still in progress. The prospective future research directions for wearable actuators include: (1) smart materials with high performance, precise control, durable, and low cost; (2) integration of smart materials into textile structures to achieve required functions; (3) exploration of more applications for wearable actuators. We expect to see the application of wearable actuators that are comparable to biological structures in all aspects in the future.

Author Contributions: Writing—original draft preparation, visualization, analysis, Y.C.; writingoriginal draft preparation, visualization, analysis, Y.Y.; writing —original draft preparation, visualization, analysis, M.L.; writing—original draft preparation, visualization, analysis, E.C.; writingoriginal draft preparation, visualization, analysis, Y.Y.; review and editing, W.M.; review and editing, R.F.; conceptualization, supervision, writing - original draft preparation, review and editing, R.Y. All authors have read and agreed to the published version of the manuscript.

Funding: This work was supported by the start-up at North Carolina State University.

Institutional Review Board Statement: Not applicable.

Informed Consent Statement: Not applicable.

Data Availability Statement: The data presented in this study are available within the manuscript.

Conflicts of Interest: The authors declare no conflict of interest.

\section{References}

1. Persson, N.K.; Martinez, J.G.; Zhong, Y.; Maziz, A.; Jager, E.W.H. Actuating Textiles: Next Generation of Smart Textiles. Adv. Mater. Technol. 2018, 3, 1700397. [CrossRef]

2. Xiong, J.; Chen, J.; Lee, P.S. Functional Fibers and Fabrics for Soft Robotics, Wearables, and Human-Robot Interface. Adv. Mater. 2021, 33, 2002640. [CrossRef]

3. Fritz, H.; Patzer, D.; Galen, S.S. Robotic exoskeletons for reengaging in everyday activities: Promises, pitfalls, and opportunities. Disabil. Rehabil. 2019, 41, 560-563. [CrossRef]

4. Mun, S.; Yun, S.; Nam, S.; Park, S.K.; Park, S.; Park, B.J.; Lim, J.M.; Kyung, K.U. Electro-Active Polymer Based Soft Tactile Interface for Wearable Devices. IEEE Trans. Haptics 2018, 11, 15-21. [CrossRef]

5. Hu, J.; Meng, H.; Li, G.; Ibekwe, S.I. A review of stimuli-responsive polymers for smart textile applications. Smart Mater. Struct. 2012, 21, 053001. [CrossRef]

6. Suman, T. Shape Memory Polymers for Smart Textile Applications. In Textiles for Advanced Applications; Kumar, B., Thakur, S., Eds.; IntechOpen: London, UK, 2017. [CrossRef]

7. O'Halloran, A.; O'Malley, F.; McHugh, P. A review on dielectric elastomer actuators, technology, applications, and challenges. J. Appl. Phys. 2008, 104, 9. [CrossRef]

8. Mirvakili, S.M.; Hunter, I.W. Artificial Muscles: Mechanisms, Applications, and Challenges. Adv. Mater. 2018, $30,1704407$. [CrossRef] [PubMed]

9. Madden, J.D.W.; Vandesteeg, N.A.; Anquetil, P.A.; Madden, P.G.A.; Takshi, A.; Pytel, R.Z.; Lafontaine, S.R.; Wieringa, P.A.; Hunter, I.W. Artificial muscle technology: Physical principles and naval prospects. IEEE J. Ocean. Eng. 2004, 29, 706-728. [CrossRef]

10. Rus, D.; Tolley, M.T. Design, fabrication and control of soft robots. Nature 2015, 521, 467-475. [CrossRef]

11. Maziz, A.; Concas, A.; Khaldi, A.; Stalhand, J.; Persson, N.K.; Jager, E.W.H. Knitting and weaving artificial muscles. Sci. Adv. 2017, 3, e1600327. [CrossRef]

12. De Volder, M.; Reynaerts, D. Pneumatic and hydraulic microactuators: A review. J. Micromech. Microeng. $2010,20,043001$. [CrossRef]

13. Otten, A.; Voort, C.; Stienen, A.; Aarts, R.; van Asseldonk, E.; van der Kooij, H. LIMPACT: A Hydraulically Powered Self-Aligning Upper Limb Exoskeleton. IEEE ASME Trans. Mechatron. 2015, 20, 2285-2298. [CrossRef]

14. Huber, J.E.; Fleck, N.A.; Ashby, M.F. The selection of mechanical actuators based on performance indices. Proc. R. Soc. London Ser. A Math. Phys. Eng. Sci. 1997, 453, 2185-2205. [CrossRef] 
15. Schaffner, M.; Faber, J.A.; Pianegonda, L.; Ruhs, P.A.; Coulter, F.; Studart, A.R. 3D printing of robotic soft actuators with programmable bioinspired architectures. Nat. Commun. 2018, 9, 878. [CrossRef]

16. Kim, S.Y.; Baines, R.; Booth, J.; Vasios, N.; Bertoldi, K.; Kramer-Bottiglio, R. Reconfigurable soft body trajectories using unidirectionally stretchable composite laminae. Nat. Commun. 2019, 10, 1-8. [CrossRef]

17. Li, S.; Vogt, D.M.; Rus, D.; Wood, R.J. Fluid-driven origami-inspired artificial muscles. Proc. Natl. Acad. Sci. USA 2017, 114, 13132-13137. [CrossRef]

18. Veale, A.J.; Xie, S.Q. Towards compliant and wearable robotic orthoses: A review of current and emerging actuator technologies. Med. Eng. Phys. 2016, 38, 317-325. [CrossRef] [PubMed]

19. Park, J.; Choi, J.; Kim, S.J.; Seo, K.-H.; Kim, J. Design of an Inflatable Wrinkle Actuator With Fast Inflation/Deflation Responses for Wearable Suits. IEEE Robot. Autom. Lett. 2020, 5, 3799-3805. [CrossRef]

20. Neill, C.T.O.; Phipps, N.S.; Cappello, L.; Paganoni, S.; Walsh, C.J. A soft wearable robot for the shoulder: Design, characterization, and preliminary testing. In Proceedings of the 2017 International Conference on Rehabilitation Robotics (ICORR), London, UK, 17-20 July 2017; pp. 1672-1678.

21. Polygerinos, P.; Wang, Z.; Galloway, K.C.; Wood, R.J.; Walsh, C.J. Soft robotic glove for combined assistance and at-home rehabilitation. Robot. Auton. Syst. 2015, 73, 135-143. [CrossRef]

22. Zhu, M.; Do, T.N.; Hawkes, E.; Visell, Y. Fluidic Fabric Muscle Sheets for Wearable and Soft Robotics. Soft Robot. 2020, 7, 179-197. [CrossRef] [PubMed]

23. Shepherd, R.F.; Stokes, A.A.; Freake, J.; Barber, J.; Snyder, P.W.; Mazzeo, A.D.; Cademartiri, L.; Morin, S.A.; Whitesides, G.M. Using Explosions to Power a Soft Robot. Angew. Chem. Int. Ed. 2013, 52, 2892-2896. [CrossRef] [PubMed]

24. Unger, M.A. Monolithic Microfabricated Valves and Pumps by Multilayer Soft Lithography. Science 2000, 288, 113-116. [CrossRef]

25. Dzahir, M.; Yamamoto, S.-I. Recent Trends in Lower-Limb Robotic Rehabilitation Orthosis: Control Scheme and Strategy for Pneumatic Muscle Actuated Gait Trainers. Robotics 2014, 3, 120-148. [CrossRef]

26. Walker, J.; Zidek, T.; Harbel, C.; Yoon, S.; Strickland, F.S.; Kumar, S.; Shin, M. Soft Robotics: A Review of Recent Developments of Pneumatic Soft Actuators. Actuators 2020, 9, 3. [CrossRef]

27. Bose, S.; Bandyopadhyay, A. Chapter 1-Introduction to Biomaterials. In Characterization of Biomaterials; Bandyopadhyay, A., Bose, S., Eds.; Academic Press: Oxford, UK, 2013. [CrossRef]

28. Sedmák, P.; Pilch, J.; Heller, L.; Kopeček, J.; Wright, J.; Sedlák, P.; Frost, M.; Šittner, P. Grain-resolved analysis of localized deformation in nickel-titanium wire under tensile load. Science 2016, 353, 559-562. [CrossRef]

29. Stachiv, I.; Alarcon, E.; Lamac, M. Shape Memory Alloys and Polymers for MEMS/NEMS Applications: Review on Recent Findings and Challenges in Design, Preparation, and Characterization. Metals 2021, 11, 415. [CrossRef]

30. Ölander, A. An electrochemical investigation of solid cadmium-gold alloys. J. Am. Chem. Soc. 1932, 54, 3819-3833. [CrossRef]

31. Huang, W. On the selection of shape memory alloys for actuators. Mater. Design 2002, 23, 11-19. [CrossRef]

32. Šittner, P.; Heller, L.; Pilch, J.; Curfs, C.; Alonso, T.; Favier, D. Young's modulus of austenite and martensite phases in superelastic NiTi wires. J. Mater. Eng. Perform. 2014, 23, 2303-2314. [CrossRef]

33. Zareie, S.; Issa, A.S.; Seethaler, R.J.; Zabihollah, A. Recent advances in the applications of shape memory alloys in civil infrastructures: A review. Structures 2020, 27, 1535-1550. [CrossRef]

34. Osada, Y.; Matsuda, A. Shape-Memory in Hydrogels. Nature 1995, 376, 219. [CrossRef]

35. Lendlein, A.; Jiang, H.Y.; Junger, O.; Langer, R. Light-induced shape-memory polymers. Nature 2005, 434, 879-882. [CrossRef] [PubMed]

36. Takeuchi, I.; Asaka, K.; Kiyohara, K.; Sugino, T.; Terasawa, N.; Mukai, K.; Fukushima, T.; Aida, T. Electromechanical behavior of fully plastic actuators based on bucky gel containing various internal ionic liquids. Electrochim. Acta 2009, 54, 1762-1768. [CrossRef]

37. Hu, J.; Zhu, Y.; Huang, H.; Lu, J. Recent advances in shape-memory polymers: Structure, mechanism, functionality, modeling and applications. Prog. Polym. Sci. 2012, 37, 1720-1763. [CrossRef]

38. Xia, Y.; He, Y.; Zhang, F.; Liu, Y.; Leng, J. A review of shape memory polymers and composites: Mechanisms, materials, and applications. Adv. Mater. 2021, 33, 2000713. [CrossRef]

39. Hadi, A.; Alipour, K.; Kazeminasab, S.; Elahinia, M. ASR glove: A wearable glove for hand assistance and rehabilitation using shape memory alloys. J. Intel. Mat. Syst. Str. 2018, 29, 1575-1585. [CrossRef]

40. Copaci, D.; Martín, F.; Moreno, L.; Blanco, D. SMA based elbow exoskeleton for rehabilitation therapy and patient evaluation. IEEE Access 2019, 7, 31473-31484. [CrossRef]

41. Serrano, D.; Copaci, D.S.; Moreno, L.; Blanco, D. SMA based wrist exoskeleton for rehabilitation therapy. In Proceedings of the 2018 IEEE/RSJ International Conference on Intelligent Robots and Systems (IROS), Madrid, Spain, 1-5 October 2018; pp. 2318-2323.

42. Kim, C.; Kim, G.; Lee, Y.; Lee, G.; Han, S.; Kang, D.; Koo, S.H.; Koh, J.-S. Shape memory alloy actuator-embedded smart clothes for ankle assistance. Smart Mater. Struct. 2020, 29, 055003. [CrossRef]

43. Yao, Z.; Linnenberg, C.; Argubi-Wollesen, A.; Weidner, R.; Wulfsberg, J.P. Biomimetic design of an ultra-compact and light-weight soft muscle glove. Prod. Eng. 2017, 11, 731-743. [CrossRef]

44. Park, S.J.; Park, C.H. Suit-type wearable robot powered by shape-memory-alloy-based fabric muscle. Sci. Rep. 2019, 9, 1-8. 
45. Copaci, D.; Cano, E.; Moreno, L.; Blanco, D. New design of a soft robotics wearable elbow exoskeleton based on shape memory alloy wire actuators. Appl. Bionics Biomech. 2017, 2017, 1605101. [CrossRef]

46. Li, Y.; Chung, S.; Chan, L.; Hu, J. Characterisation of shape memory fabrics. Text. Asia 2004, 35, 32-37.

47. Principles of SMP's Environmental Temperature Adaption Feature. Available online: https://www.mcf.co.jp/en/service/ diaseries/diaplex.html (accessed on 17 May 2021).

48. Kim, H.; Lee, H.; Ha, I.; Jung, J.; Won, P.; Cho, H.; Yeo, J.; Hong, S.; Han, S.; Kwon, J. Biomimetic color changing anisotropic soft actuators with integrated metal nanowire percolation network transparent heaters for soft robotics. Adv. Funct. Mater. 2018, $28,1801847$. [CrossRef]

49. Yao, S.; Cui, J.; Cui, Z.; Zhu, Y. Soft electrothermal actuators using silver nanowire heaters. Nanoscale 2017, 9, 3797-3805. [CrossRef] [PubMed]

50. Yin, R.; Yang, B.; Ding, X.; Liu, S.; Zeng, W.; Li, J.; Yang, S.; Tao, X. Wireless Multistimulus-Responsive Fabric-Based Actuators for Soft Robotic, Human-Machine Interactive, and Wearable Applications. Adv. Mater. Technol. 2020, 5, 2000341. [CrossRef]

51. Yu, W.; Chu, C. Textile Physics; Donghua University Press: Shanghai, China, 2002; pp. 2-25.

52. Zhu, Q.; Jin, Y.; Wang, W.; Sun, G.; Wang, D. Bioinspired Smart Moisture Actuators Based on Nanoscale Cellulose Materials and Porous, Hydrophilic EVOH Nanofibrous Membranes. ACS Appl. Mater. Inter. 2018, 11, 1440-1448. [CrossRef] [PubMed]

53. Wang, M.; Tian, X.; Ras, R.H.; Ikkala, O. Sensitive Humidity-Driven Reversible and Bidirectional Bending of Nanocellulose Thin Films as Bio-Inspired Actuation. Adv. Mater. Interfaces 2015, 2, 1500080. [CrossRef]

54. Mirvakili, S.M.; Hunter, I.W. Multidirectional artificial muscles from nylon. Adv. Mater. 2017, 29, 1604734. [CrossRef]

55. Kanik, M.; Orguc, S.; Varnavides, G.; Kim, J.; Benavides, T.; Gonzalez, D.; Akintilo, T.; Tasan, C.C.; Chandrakasan, A.P.; Fink, Y. Strain-programmable fiber-based artificial muscle. Science 2019, 365, 145-150. [PubMed]

56. Acetate-Based Conjugate Fiber Ventcool ${ }^{\mathrm{TM}}$. Available online: https://www.m-chemical.co.jp/en/products/departments/mcc/ fibersmat/product/1201225_7496.html (accessed on 17 May 2021).

57. Jia, T.J.; Wang, Y.; Dou, Y.Y.; Li, Y.W.; de Andrade, M.J.; Wang, R.; Fang, S.L.; Li, J.J.; Yu, Z.; Qiao, R.; et al. Moisture Sensitive Smart Yarns and Textiles from Self-Balanced Silk Fiber Muscles. Adv. Funct. Mater. 2019, 29, 1808241. [CrossRef]

58. Cheng, H.; Hu, Y.; Zhao, F.; Dong, Z.; Wang, Y.; Chen, N.; Zhang, Z.; Qu, L. Moisture-activated torsional graphene-fiber motor. Adv. Mater. 2014, 26, 2909-2913. [CrossRef]

59. He, S.; Chen, P.; Qiu, L.; Wang, B.; Sun, X.; Xu, Y.; Peng, H. A mechanically actuating carbon-nanotube fiber in response to water and moisture. Angew. Chem. Int. Ed. 2015, 54, 14880-14884. [CrossRef] [PubMed]

60. Hu, X.; Leng, X.; Jia, T.; Liu, Z. Twisted and coiled bamboo artificial muscles for moisture responsive torsional and tensile actuation. Chin. Phys. B 2020, 29, 118103. [CrossRef]

61. Li, Y.; Leng, X.; Sun, J.; Zhou, X.; Wu, W.; Chen, H.; Liu, Z. Moisture-sensitive torsional cotton artificial muscle and textile. Chin. Phys. B 2020, 29, 048103. [CrossRef]

62. Wang, Y.; Wang, Z.; Lu, Z.; Jung de Andrade, M.N.; Fang, S.; Zhang, Z.; Wu, J.; Baughman, R.H. Humidity-and Water-Responsive Torsional and Contractile Lotus Fiber Yarn Artificial Muscles. ACS Appl. Mater. Inter. 2021, 13, 6642-6649. [CrossRef]

63. Mirabedini, A.; Aziz, S.; Spinks, G.M.; Foroughi, J. Wet-spun biofiber for torsional artificial muscles. Soft Robot. 2017, 4, 421-430. [CrossRef] [PubMed]

64. Zhang, Z.; Zhu, B.; Peng, Z.; Yin, R.; Baughman, R.H.; Tao, X. Programmable and thermally hardening composite yarn actuators with a wide range of operating temperature. Adv. Mater. Technol. 2020, 5, 2000329. [CrossRef]

65. Haines, C.S.; Lima, M.D.; Li, N.; Spinks, G.M.; Foroughi, J.; Madden, J.D.W.; Kim, S.H.; Fang, S.L.; de Andrade, M.J.; Goktepe, F.; et al. Artificial Muscles from Fishing Line and Sewing Thread. Science 2014, 343, 868-872. [CrossRef] [PubMed]

66. Yang, X.H.; Wang, W.H.; Miao, M.H. Moisture-Responsive Natural Fiber Coil-Structured Artificial Muscles. ACS Appl. Mater. Inter. 2018, 10, 32256-32264. [CrossRef] [PubMed]

67. Li, Y.; Miao, M. Water-responsive artificial muscles from commercial viscose fibers without chemical treatment. Mater. Res. Lett. 2020, 8, 232-238. [CrossRef]

68. Lamuta, C.; Messelot, S.; Tawfick, S. Theory of the tensile actuation of fiber reinforced coiled muscles. Smart Mater. Struct. 2018, 27, 055018. [CrossRef]

69. Peng, Y.; Cui, Y. Advanced textiles for personal thermal management and energy. Joule 2020, 4, 724-742. [CrossRef]

70. Zhong, Y.; Zhang, F.; Wang, M.; Gardner, C.J.; Kim, G.; Liu, Y.; Leng, J.; Jin, S.; Chen, R. Reversible humidity sensitive clothing for personal thermoregulation. Sci. Rep. 2017, 7, 1-8. [CrossRef]

71. Zhang, X.A.; Yu, S.; Xu, B.; Li, M.; Peng, Z.; Wang, Y.; Deng, S.; Wu, X.; Wu, Z.; Ouyang, M. Dynamic gating of infrared radiation in a textile. Science 2019, 363, 619-623. [CrossRef] [PubMed]

72. Wang, W.; Yao, L.; Cheng, C.-Y.; Zhang, T.; Atsumi, H.; Wang, L.; Wang, G.; Anilionyte, O.; Steiner, H.; Ou, J. Harnessing the hygroscopic and biofluorescent behaviors of genetically tractable microbial cells to design biohybrid wearables. Sci. Adv. 2017, 3, e1601984. [CrossRef]

73. Qiu, Y.; Zhang, E.; Plamthottam, R.; Pei, Q. Dielectric Elastomer Artificial Muscle: Materials Innovations and Device Explorations. Acc. Chem. Res. 2019, 52, 316-325. [CrossRef]

74. Pelrine, R.E.; Kornbluh, R.D.; Joseph, J.P. Electrostriction of polymer dielectrics with compliant electrodes as a means of actuation. Sens. Actuators A Phys. 1998, 64, 77-85. [CrossRef] 
75. Pelrine, R.; Kornbluh, R.; Pei, Q.; Joseph, J. High-Speed Electrically Actuated Elastomers with Strain Greater Than $100 \%$. Science 2000, 287, 836. [CrossRef]

76. Shankar, R.; Ghosh, T.K.; Spontak, R.J. Dielectric elastomers as next-generation polymeric actuators. Soft Matter 2007, 3, 1116-1129. [CrossRef] [PubMed]

77. Romasanta, L.J.; Lopez-Manchado, M.A.; Verdejo, R. Increasing the performance of dielectric elastomer actuators: A review from the materials perspective. Prog. Polym. Sci. 2015, 51, 188-211. [CrossRef]

78. Youn, J.-H.; Jeong, S.M.; Hwang, G.; Kim, H.; Hyeon, K.; Park, J.; Kyung, K.-U. Dielectric Elastomer Actuator for Soft Robotics Applications and Challenges. Appl. Sci. 2020, 10, 640. [CrossRef]

79. Brochu, P.; Pei, Q. Advances in Dielectric Elastomers for Actuators and Artificial Muscles. Macromol. Rapid Commun. 2010, 31, 10-36. [CrossRef]

80. Kovacs, G.; Düring, L.; Michel, S.; Terrasi, G. Stacked dielectric elastomer actuator for tensile force transmission. Sens. Actuators A: Phys. 2009, 155, 299-307. [CrossRef]

81. Chortos, A.; Hajiesmaili, E.; Morales, J.; Clarke, D.R.; Lewis, J.A. 3D Printing of Interdigitated Dielectric Elastomer Actuators. Adv. Funct. Mater. 2020, 30, 1907375. [CrossRef]

82. Jung, H.S.; Yang, S.Y.; Cho, K.H.; Song, M.G.; Nguyen, C.T.; Phung, H.; Kim, U.; Moon, H.; Koo, J.C.; Nam, J.-D.; et al. Design and fabrication of twisted monolithic dielectric elastomer actuator. Int. J. Control Autom. Syst. 2017, 15, 25-35. [CrossRef]

83. Zhao, H.; Hussain, A.M.; Duduta, M.; Vogt, D.M.; Wood, R.J.; Clarke, D.R. Compact Dielectric Elastomer Linear Actuators. Adv. Funct. Mater. 2018, 28, 1804328. [CrossRef]

84. Phung, H.; Nguyen, C.T.; Jung, H.; Nguyen, T.D.; Choi, H.R. Bidirectional tactile display driven by electrostatic dielectric elastomer actuator. Smart Mater. Struct. 2020, 29, 035007. [CrossRef]

85. Nalbach, S.; Banda, R.M.; Croce, S.; Rizzello, G.; Naso, D.; Seelecke, S. Modeling and Design Optimization of a Rotational Soft Robotic System Driven by Double Cone Dielectric Elastomer Actuators. Front. Robot. AI 2020, 6, 150. [CrossRef]

86. Rosset, S.; Niklaus, M.; Dubois, P.; Shea, H.R. Large-Stroke Dielectric Elastomer Actuators With Ion-Implanted Electrodes. J. Microelectromechanical Syst. 2009, 18, 1300-1308. [CrossRef]

87. Liang, D.; Lin, Z.-F.; Huang, C.-C.; Shih, W.-P. Tunable lens driven by dielectric elastomer actuator with ionic electrodes. Micro Nano Lett. 2014, 9, 869-873. [CrossRef]

88. Qu, X.; Ma, X.; Shi, B.; Li, H.; Zheng, L.; Wang, C.; Liu, Z.; Fan, Y.; Chen, X.; Li, Z.; et al. Refreshable Braille Display System Based on Triboelectric Nanogenerator and Dielectric Elastomer. Adv. Funct. Mater. 2021, 31, 2006612. [CrossRef]

89. Duduta, M.; Wood, R.J.; Clarke, D.R. Multilayer Dielectric Elastomers for Fast, Programmable Actuation without Prestretch. Adv. Mater. 2016, 28, 8058-8063. [CrossRef]

90. Shao, H.; Wei, S.; Jiang, X.; Holmes, D.P.; Ghosh, T.K. Bioinspired Electrically Activated Soft Bistable Actuators. Adv. Funct. Mater. 2018, 28, 1802999. [CrossRef]

91. Pei, Q.; Rosenthal, M.; Stanford, S.; Prahlad, H.; Pelrine, R. Multiple-degrees-of-freedom electroelastomer roll actuators. Smart Mater. Struct. 2004, 13, N86-N92. [CrossRef]

92. Yan, Y.; Santaniello, T.; Bettini, L.G.; Minnai, C.; Bellacicca, A.; Porotti, R.; Denti, I.; Faraone, G.; Merlini, M.; Lenardi, C.; et al. Electroactive Ionic Soft Actuators with Monolithically Integrated Gold Nanocomposite Electrodes. Adv. Mater. 2017, $29,1606109$. [CrossRef] [PubMed]

93. Pyo, D.; Ryu, S.; Kyung, K.-U.; Yun, S.; Kwon, D.-S. High-pressure endurable flexible tactile actuator based on microstructured dielectric elastomer. Appl. Phys. Lett. 2018, 112, 061902. [CrossRef]

94. Acome, E.; Keplinger, C.; Gross, M.D.; Bruns, C.; Leithinger, D. Soft Electrohydraulic Actuators for Origami Inspired ShapeChanging Interfaces. In Proceedings of the CHI '21 Extended Abstracts, Yokohama, Japan, 8-13 May 2021.

95. Ren, Z.; Hu, W.; Liu, C.; Li, S.; Niu, X.; Pei, Q. Phase-Changing Bistable Electroactive Polymer Exhibiting Sharp Rigid-to-Rubbery Transition. Macromolecules 2016, 49, 134-140. [CrossRef]

96. Ji, X.; Liu, X.; Cacucciolo, V.; Civet, Y.; El Haitami, A.; Cantin, S.; Perriard, Y.; Shea, H. Untethered Feel-Through Haptics Using 18- $\mu \mathrm{m}$ Thick Dielectric Elastomer Actuators. Adv. Funct. Mater. 2020, 2006639. [CrossRef]

97. Lee, H.S.; Phung, H.; Lee, D.-H.; Kim, U.K.; Nguyen, C.T.; Moon, H.; Koo, J.C.; Nam, J.-D.; Choi, H.R. Design analysis and fabrication of arrayed tactile display based on dielectric elastomer actuator. Sens. Actuators A Phys. 2014, 205, 191-198. [CrossRef]

98. King, H.H.; Donlin, R.; Hannaford, B. Perceptual thresholds for single vs. Multi-Finger Haptic interaction. In Proceedings of the 2010 IEEE Haptics Symposium, Waltham, MA, USA, 25-26 March 2010; pp. 95-99.

99. Leroy, E.; Hinchet, R.; Shea, H. Multimode Hydraulically Amplified Electrostatic Actuators for Wearable Haptics. Adv. Mater. 2020, 32, 2002564. [CrossRef]

100. Koo, I.M.; Jung, K.; Koo, J.C.; Nam, J.; Lee, Y.K.; Choi, H.R. Development of Soft-Actuator-Based Wearable Tactile Display. IEEE Trans. Robot. 2008, 24, 549-558. [CrossRef]

101. Zhao, H.; Hussain, A.M.; Israr, A.; Vogt, D.M.; Duduta, M.; Clarke, D.R.; Wood, R.J. A Wearable Soft Haptic Communicator Based on Dielectric Elastomer Actuators. Soft Robot. 2020, 7, 451-461. [CrossRef]

102. Carpi, F.; Mannini, A.; de Rossi, D. Elastomeric contractile actuators for hand rehabilitation splints. In Proceedings of the SPIE Smart Structures and Materials + Nondestructive Evaluation and Health Monitoring, San Diego, CA, USA, 29 April 2008.

103. Pourazadi, S.; Ahmadi, S.; Menon, C. Towards the development of active compression bandages using dielectric elastomer actuators. Smart Mater. Struct. 2014, 23, 065007. [CrossRef] 
104. Allen, D.P.; Little, R.; Laube, J.; Warren, J.; Voit, W.; Gregg, R.D. Towards an ankle-foot orthosis powered by a dielectric elastomer actuator. Mechatronics 2021, 76, 102551. [CrossRef]

105. Kim, K.J.; Shahinpoor, M. Ionic polymer metal composites: II. Manufacturing techniques. Smart Mater. Struct. 2003, 12, 65-79. [CrossRef]

106. Kuhn, H.; Möbius, D. Systems of Monomolecular Layers-Assembling and Physico-Chemical Behavior. Angew. Chem. Int. Ed. Engl. 1971, 10, 620-637. [CrossRef]

107. Katchalsky, A. Rapid swelling and deswelling of reversible gels of polymeric acids by ionization. Experientia 1949, 5, 319-320. [CrossRef]

108. Shahinpoor, M.; Kim, K.J. Ionic polymer-metal composites: I. Fundamentals. Smart Mater. Struct. 2001, 10, 819-833. [CrossRef]

109. Asaka, K.; Mukai, K.; Sugino, T.; Kiyohara, K. Ionic electroactive polymer actuators based on nano-carbon electrodes. Polym. Int. 2013, 62, 1263-1270. [CrossRef]

110. Wang, H.S.; Cho, J.; Park, H.W.; Jho, J.Y.; Park, J.H. Ionic polymer-metal composite actuators driven by methylammonium formate for high-voltage and long-term operation. J. Ind. Eng. Chem. 2021, 96, 194-201. [CrossRef]

111. Bar-Cohen, Y. Electroactive Polymer (EAP) Actuators as Artificial Muscles: Reality, Potential, and Challenges; SPIE: Bellingham, WA USA, 2004.

112. Zou, M.; Li, S.; Hu, X.; Leng, X.; Wang, R.; Zhou, X.; Liu, Z. Progresses in Tensile, Torsional, and Multifunctional Soft Actuators. Adv. Funct. Mater. 2021, 2007437. [CrossRef]

113. Wu, Y.; Yang, Y.; Li, C.; Li, Y.; Chen, W. Flexible and Electroactive Textile Actuator Enabled by PEDOT:PSS/MOF-Derivative Electrode Ink. Front. Bioeng. Biotechnol. 2020, 8, 212. [CrossRef] [PubMed]

114. Li, Y.; Hashimoto, M. PVC gel soft actuator-based wearable assist wear for hip joint support during walking. Smart Mater. Struct. 2017, 26, 125003. [CrossRef]

115. Chattaraj, R.; Bhaumik, S.; Khan, S.; Chatterjee, D. Soft wearable ionic polymer sensors for palpatory pulse-rate extraction. Sens. Actuators A Phys. 2018, 270, 65-71. [CrossRef]

116. Hamlen, R.P.; Kent, C.E.; Shafer, S.N. Electrolytically Activated Contractile Polymer. Nature 1965, 206, 1149-1150. [CrossRef]

117. Lu, W.; Fadeev, A.G.; Qi, B.; Smela, E.; Mattes, B.R.; Ding, J.; Spinks, G.M.; Mazurkiewicz, J.; Zhou, D.; Wallace, G.G.; et al. Use of Ionic Liquids for $\pi$-Conjugated Polymer Electrochemical Devices. Science 2002, 297, 983. [CrossRef]

118. Lewis, T.W.; Spinks, G.M.; Wallace, G.G.; Mazzoldi, A.; De Rossi, D. Investigation of the applied potential limits for polypyrrole when employed as the active components of a two-electrode device. Synth. Met. 2001, 122, 379-385. [CrossRef]

119. Chen, D.; Guorong, L.; Yin, Q. Piezoelectric Constants Measured from Converse Piezoelectric Effect and Piezoelectric Ceramic Actuators. J. Inorg. Mater. 1997, 12, 861-866.

120. Brook, R.J. Advanced Ceramic Materials: An Overview. In Concise Encyclopedia of Advanced Ceramic Materials; Brook, R.J., Ed.; Pergamon: Oxford, UK, 1991; pp. 1-8.

121. Sun, Q.; Wang, J.; Zhang, L.; Mao, P.; Liu, S.; He, L.; Kang, F.; Xue, R. Achieving high energy density and discharge efficiency in multi-layered PVDF-PMMA nanocomposites composed of $0 \mathrm{D} \mathrm{BaTiO}_{3}$ and $1 \mathrm{D} \mathrm{NaNbO}_{3} @ \mathrm{SiO}_{2}$. J. Mater. Chem. C 2020, 8, 7211-7220. [CrossRef]

122. Akther, A.; Castro, J.O.; Mousavi Shaegh, S.A.; Rezk, A.R.; Yeo, L.Y. Miniaturised acoustofluidic tactile haptic actuator. Soft Matter 2019, 15, 4146-4152. [CrossRef] [PubMed]

123. Wu, Y.; Yim, J.K.; Liang, J.; Shao, Z.; Qi, M.; Zhong, J.; Luo, Z.; Yan, X.; Zhang, M.; Wang, X.; et al. Insect-scale fast moving and ultrarobust soft robot. Sci. Robot. 2019, 4, eaax1594. [CrossRef]

124. Maccabi, N.; Grinberg, I.; Kassie, A.; Shmulevich, S.; Elata, D. Bulk PZT Actuator for Parallel out-of-plane motion: The Superiority of Torsion Deformation over Bending Deformation. Procedia Eng. 2016, 168, 1513-1516. [CrossRef]

125. Xu, C.; Reng, Y.; Liu, S.; Zhu, J.; Liu, Y.; Wu, H. A fast rotating soft actuator based on piezoelectric vibration. Chin. Sci. Bull. 2020, 65, 109-116. [CrossRef]

126. Kwon, O.D.; Yoo, J.S.; Yun, Y.J.; Lee, J.S.; Kang, S.H.; Lim, K.J. A research on the piezoelectric vibration actuator for mobile phone. In Proceedings of the 2005 International Symposium on Electrical Insulating Materials, 2005. (ISEIM 2005), Kitakyushu, Japan, 5-9 June 2005; Volume 673, pp. 676-678.

127. Park, T.; Cha, Y. Soft mobile robot inspired by animal-like running motion. Sci. Rep. 2019, 9, 14700. [CrossRef]

128. Jeong, S.-S.; Cheon, S.-K.; Kim, M.-H.; Song, J.-S.; Park, T.-G. Motional characteristics of ultrasonic motor using $\Lambda$ (lambda)-shaped stator. Ceram. Int. 2013, 39, S715-S719. [CrossRef]

129. Li, X.; Yao, Z.; Wu, R. Modeling and analysis of stick-slip motion in a linear piezoelectric ultrasonic motor considering ultrasonic oscillation effect. Int. J. Mech. Sci. 2016, 107, 215-224. [CrossRef]

130. Qiu, W.; Mizuno, Y.; Koyama, D.; Nakamura, K. Efficiency improvement of hybrid transducer-type ultrasonic motor using lubricant. IEEE Trans. Ultrason. Ferroelectr. Freq. Control 2013, 60, 786-794. [CrossRef] [PubMed]

131. Tian, X.; Liu, Y.; Deng, J.; Wang, L.; Chen, W. A review on piezoelectric ultrasonic motors for the past decade: Classification, operating principle, performance, and future work perspectives. Sens. Actuators A Phys. 2020, 306, 111971. [CrossRef]

132. Sauvet, B.; Laliberté, T.; Gosselin, C. Design, analysis and experimental validation of an ungrounded haptic interface using a piezoelectric actuator. Mechatronics 2017, 45, 100-109. [CrossRef]

133. Zhu, M.; Sun, Z.; Zhang, Z.; Shi, Q.; He, T.; Liu, H.; Chen, T.; Lee, C. Haptic-feedback smart glove as a creative human-machine interface (HMI) for virtual/augmented reality applications. Sci. Adv. 2020, 6, eaaz8693. [CrossRef] 
134. Dagdeviren, C.; Shi, Y.; Joe, P.; Ghaffari, R.; Balooch, G.; Usgaonkar, K.; Gur, O.; Tran, P.L.; Crosby, J.R.; Meyer, M.; et al. Conformal piezoelectric systems for clinical and experimental characterization of soft tissue biomechanics. Nat. Mater. 2015, 14, 728-736. [CrossRef]

135. Ba, J. Research on Magnetically Controlled Miniature Soft Crawling Robot Based on Magneto-elastic Composite Material. Ph.D. Thesis, Tianjin University of Technology, Tianjin, China, 2020.

136. Mao, G.; Drack, M.; Karami-Mosammam, M.; Wirthl, D.; Stockinger, T.; Schwödiauer, R.; Kaltenbrunner, M. Soft electromagnetic actuators. Sci. Adv. 2020, 6, eabc0251. [CrossRef]

137. Ebrahimi, N.; Schimpf, P.; Jafari, A. Design optimization of a solenoid-based electromagnetic soft actuator with permanent magnet core. Sens. Actuators A Phys. 2018, 284, 276-285. [CrossRef]

138. Pece, F.; Zarate, J.J.; Vechev, V.; Besse, N.; Gudozhnik, O.; Shea, H.; Hilliges, O. MagTics: Flexible and Thin Form Factor Magnetic Actuators for Dynamic and Wearable Haptic Feedback. In Proceedings of the 30th Annual ACM Symposium on User Interface Software and Technology, Québec City, QC, Canada, 20 October 2017; pp. 143-154.

139. Yunas, J.; Mulyanti, B.; Hamidah, I.; Mohd Said, M.; Pawinanto, R.E.; Wan Ali, W.A.; Subandi, A.; Hamzah, A.A.; Latif, R.; Yeop Majlis, B. Polymer-Based MEMS Electromagnetic Actuator for Biomedical Application: A Review. Polymers 2020, $12,1184$. [CrossRef]

140. Do, T.N.; Phan, H.; Nguyen, T.-Q.; Visell, Y. Miniature Soft Electromagnetic Actuators for Robotic Applications. Adv. Funct. Mater. 2018, 28, 1800244. [CrossRef]

141. Guo, R.; Sheng, L.; Gong, H.; Liu, J. Liquid metal spiral coil enabled soft electromagnetic actuator. Sci. China Technol. Sci. 2018, 61, 516-521. [CrossRef]

142. Ozioko, O.; Navaraj, W.; Hersh, M.; Dahiya, R. Tacsac: A Wearable Haptic Device with Capacitive Touch-Sensing Capability for Tactile Display. Sensors 2020, 20, 4780. [CrossRef]

143. Ozioko, O.; Karipoth, P.; Hersh, M.; Dahiya, R. Wearable Assistive Tactile Communication Interface Based on Integrated Touch Sensors and Actuators. IEEE Trans. Neural Syst. Rehabil. Eng. 2020, 28, 1344-1352. [CrossRef] [PubMed]

144. Yu, X.; Xie, Z.; Yu, Y.; Lee, J.; Vazquez-Guardado, A.; Luan, H.; Ruban, J.; Ning, X.; Akhtar, A.; Li, D.; et al. Skin-integrated wireless haptic interfaces for virtual and augmented reality. Nature 2019, 575, 473-479. [CrossRef]

145. White, T.J.; Broer, D.J. Programmable and adaptive mechanics with liquid crystal polymer networks and elastomers. Nat. Mater. 2015, 14, 1087-1098. [CrossRef] [PubMed]

146. Kularatne, R.S.; Kim, H.; Boothby, J.M.; Ware, T.H. Liquid Crystal Elastomer Actuators: Synthesis, Alignment, and Applications. J. Polym. Sci. Pol. Phys. 2017, 55, 395-411. [CrossRef]

147. Ohm, C.; Brehmer, M.; Zentel, R. Liquid Crystalline Elastomers as Actuators and Sensors. Adv. Mater. 2010, $22,3366-3387$. [CrossRef]

148. He, Q.; Wang, Z.; Wang, Y.; Minori, A.; Tolley, M.T.; Cai, S. Electrically controlled liquid crystal elastomer-based soft tubular actuator with multimodal actuation. Sci. Adv. 2019, 5, 10. [CrossRef] [PubMed]

149. Yakacki, C.M.; Saed, M.; Nair, D.P.; Gong, T.; Reed, S.M.; Bowman, C.N. Tailorable and programmable liquid-crystalline elastomers using a two-stage thiol-acrylate reaction. Rsc. Adv. 2015, 5, 18997-19001. [CrossRef]

150. Liu, H.R.; Tian, H.M.; Shao, J.Y.; Wang, Z.J.; Li, X.M.; Wang, C.H.; Chen, X.L. An Electrically Actuated Soft Artificial Muscle Based on a High-Performance Flexible Electrothermal Film and Liquid-Crystal Elastomer. Acs. Appl. Mater. Inter. 2020, 12, 56338-56349. [CrossRef]

151. Wang, Y.C.; Dang, A.L.; Zhang, Z.F.; Yin, R.; Gao, Y.C.; Feng, L.; Yang, S. Repeatable and Reprogrammable Shape Morphing from Photoresponsive Gold Nanorod/Liquid Crystal Elastomers. Adv. Mater. 2020, 32, 2004270. [CrossRef] [PubMed]

152. Wang, M.; Sayed, S.M.; Guo, L.X.; Lin, B.P.; Zhang, X.Q.; Sun, Y.; Yang, H. Multi-Stimuli Responsive Carbon Nanotube Incorporated Polysiloxane Azobenzene Liquid Crystalline Elastomer Composites. Macromolecules 2016, 49, 663-671. [CrossRef]

153. Ambulo, C.P.; Ford, M.J.; Searles, K.; Majidi, C.; Ware, T.H. 4D-Printable Liquid Metal-Liquid Crystal Elastomer Composites. Acs. Appl. Mater. Inter. 2021, 13, 12805-12813. [CrossRef]

154. Lu, X.L.; Guo, S.W.; Tong, X.; Xia, H.S.; Zhao, Y. Tunable Photocontrolled Motions Using Stored Strain Energy in Malleable Azobenzene Liquid Crystalline Polymer Actuators. Adv. Mater. 2017, 29, 1606467. [CrossRef]

155. Zeng, H.; Wani, O.M.; Wasylczyk, P.; Kaczmarek, R.; Priimagi, A. Self-Regulating Iris Based on Light-Actuated Liquid Crystal Elastomer. Adv. Mater. 2017, 29, 1701814. [CrossRef] [PubMed]

156. Roach, D.J.; Yuan, C.; Kuang, X.; Li, V.C.F.; Blake, P.; Romero, M.L.; Hammel, I.; Yu, K.; Qi, H.J. Long Liquid Crystal Elastomer Fibers with Large Reversible Actuation Strains for Smart Textiles and Artificial Muscles. Acs. Appl. Mater. Inter. 2019, 11, 19514-19521. [CrossRef]

157. He, Q.G.; Wang, Z.J.; Song, Z.Q.; Cai, S.Q. Bioinspired Design of Vascular Artificial Muscle. Adv. Mater. Technol. 2019, 4, 1800244. [CrossRef]

158. Yoon, H.H.; Kim, D.Y.; Jeong, K.U.; Ahn, S.K. Surface Aligned Main-Chain Liquid Crystalline Elastomers: Tailored Properties by the Choice of Amine Chain Extenders. Macromolecules 2018, 51, 1141-1149. [CrossRef]

159. Saed, M.O.; Ambulo, C.P.; Kim, H.; De, R.; Raval, V.; Searles, K.; Siddiqui, D.A.; Cue, J.M.O.; Stefan, M.C.; Shankar, M.R.; et al. Molecularly-Engineered, 4D-Printed Liquid Crystal Elastomer Actuators. Adv. Funct. Mater. 2019, 29, 1806412. [CrossRef]

160. Butzer, T.; Lambercy, O.; Arata, J.; Gassert, R. Fully Wearable Actuated Soft Exoskeleton for Grasping Assistance in Everyday Activities. Soft Robot. 2021, 8, 128-143. [CrossRef] 
161. Kim, J.; Lee, G.; Heimgartner, R.; Arumukhom Revi, D.; Karavas, N.; Nathanson, D.; Galiana, I.; Eckert-Erdheim, A.; Murphy, P.; Perry, D.; et al. Reducing the metabolic rate of walking and running with a versatile, portable exosuit. Science 2019, 365, 668-672. [CrossRef]

162. Zang, X.; Zhou, Q.; Chang, J.; Liu, Y.; Lin, L. Graphene and carbon nanotube (CNT) in MEMS/NEMS applications. Microelectron. Eng. 2015, 132, 192-206. [CrossRef]

163. Jang, Y.; Kim, S.M.; Spinks, G.M.; Kim, S.J. Carbon Nanotube Yarn for Fiber-Shaped Electrical Sensors, Actuators, and Energy Storage for Smart Systems. Adv. Mater. 2020, 32, e1902670. [CrossRef]

164. Haines, C.S.; Li, N.; Spinks, G.M.; Aliev, A.E.; Di, J.; Baughman, R.H. New twist on artificial muscles. Proc. Natl. Acad. Sci. USA 2016, 113, 11709-11716. [CrossRef] [PubMed]

165. Rogers, G.W.; Liu, J.Z. Graphene actuators: Quantum-mechanical and electrostatic double-layer effects. J. Am. Chem. Soc. 2011, 133, 10858-10863. [CrossRef] [PubMed]

166. Lee, J.A.; Kim, Y.T.; Spinks, G.M.; Suh, D.; Lepro, X.; Lima, M.D.; Baughman, R.H.; Kim, S.J. All-solid-state carbon nanotube torsional and tensile artificial muscles. Nano Lett. 2014, 14, 2664-2669. [CrossRef]

167. Foroughi, J.; Spinks, G.M.; Wallace, G.G.; Oh, J.; Kozlov, M.E.; Fang, S.; Mirfakhrai, T.; Madden, J.D.; Shin, M.K.; Kim, S.J.; et al. Torsional carbon nanotube artificial muscles. Science 2011, 334, 494-497. [CrossRef] [PubMed]

168. Kim, K.J.; Hyeon, J.S.; Kim, H.; Mun, T.J.; Haines, C.S.; Li, N.; Baughman, R.H.; Kim, S.J. Enhancing the Work Capacity of Electrochemical Artificial Muscles by Coiling Plies of Twist-Released Carbon Nanotube Yarns. ACS Appl. Mater. Interfaces 2019, 11, 13533-13537. [CrossRef]

169. Lin, H.; Zhang, S.; Xiao, Y.; Zhang, C.; Zhu, J.; Dunlop, J.W.C.; Yuan, J. Organic Molecule-Driven Polymeric Actuators. Macromol. Rapid Commun. 2019, 40, e1800896. [CrossRef] [PubMed]

170. Scheidl, R.; Winkler, B.; Kogler, H.; Ladner, P.; Haas, R.; Lukachev, E. Digital Fluid Technologies for the Steel Industry. BHM Berg Hüttenmännische Mon. 2016, 161, 504-509. [CrossRef]

171. Yang, T.-H.; Kim, J.R.; Jin, H.; Gil, H.; Koo, J.-H.; Kim, H.J. Recent Advances and Opportunities of Active Materials for Haptic Technologies in Virtual and Augmented Reality. Adv. Funct. Mater. 2021, 2008831. [CrossRef] 